Manuscript for submission to Combustion Science and Technology

\title{
Sounding Rocket Microgravity Experiments Elucidating Diffusive and Radiative Transport Effects on Flame Spread over Thermally-Thick Solids
}

\author{
S.L. Olson, NASA Glenn Research Center* \\ U. Hegde, National Center for Microgravity Research \\ S. Bhattacharjee, San Diego State University \\ J.L. Deering, Washington State University \\ L. Tang, Washington State University \\ R.A. Altenkirch,New Jersey Institute of Technology
}

Short Title:

Microgravity Flame Spread over Thick Solids

Keywords: microgravity, flame spread, thick solid, radiation, opposed flow

\author{
* corresponding author \\ Dr. Sandra L. Olson \\ mail stop 77-5; 21000 Brookpark Rd. \\ NASA Glenn Research Center \\ Cleveland, $\mathrm{OH} 44135$ USA \\ fax (216) 977-7065 phone (216) 433-2859 email sandra.olson@ grc.nasa.gov
}

This report is a preprint of an article submitted to a journal for publication. Because of changes that may be made before formal publication, this preprint is made available with the understanding that it will not be cited or reproduced without the permission of the author. 


\title{
Sounding Rocket Microgravity Experiments Elucidating Diffusive and Radiative Transport Effects on Flame Spread over Thermally-Thick Solids
}

\author{
S.L. Olson, NASA Glenn Research Center* \\ U. Hegde, National Center for Microgravity Research \\ S. Bhattacharjee, San Diego State University \\ J.L. Deering, Washington State University \\ L. Tang, Washington State University \\ R.A. Altenkirch, Mississippi State University
}

\begin{abstract}
$\underline{\text { Abstract }}$
A series of 6-minute microgravity combustion experiments of opposed flow flame spread over thermally-thick PMMA has been conducted to extend data previously reported at high opposed flows to almost two decades lower in flow. The effect of flow velocity on flame spread shows a square root power law dependence rather than the linear dependence predicted by thermal theory. The experiments demonstrate that opposed flow flame spread is viable to very low velocities and more robust than expected from the numerical model, which predicts that at very low velocities $(<5 \mathrm{~cm} / \mathrm{s})$, flame spread rates fall off more rapidly as flow is reduced. It is hypothesized that the enhanced flame spread observed in the experiments may be due to threedimensional hydrodynamic effects, which are not included in the zero-gravity, two-dimensional hydrodynamic model. The effect of external irradiation was found to be more complex than the model predicted over the $0-2 \mathrm{~W} / \mathrm{cm}^{2}$ range. In the experiments, the flame compensated for the increased irradiation by stabilizing farther from the surface. A surface energy balance reveals that the imposed flux was at least partially offset by a reduced conductive flux from the increased standoff distance, so that the effect on flame spread was weaker than anticipated.
\end{abstract}




\section{$\underline{\text { Introduction }}$}

With few exceptions, research on microgravity flame spread over solid materials has been focused on thermally-thin fuels due to constraints on test time or allowable heat release rates (T'ien et al., 2001). This paper provides a detailed analysis of the results of a series of sounding rocket microgravity combustion experiments of flame spread over thermally-thick PMMA varying very low velocity opposed flow and external radiant heat flux that have previously only been described briefly (Olson et al, 1997; Altenkirch et al., 1999).

One of the few experiments on thermally thick fuels was performed during a Space Shuttle flight inside a sealed chamber (Altenkirch et al., 1998). In this microgravity experiment, a thermally-thick PMMA sample was burned in a quiescent atmosphere of $50 \% \mathrm{O}_{2}$ and $50 \% \mathrm{~N}_{2}$ at $1 \mathrm{~atm}$ pressure. The analysis showed that as the spreading flame consumed oxygen, the diffusion length increased more rapidly than the rate of flame spread, and the rate of oxygen transport to the flame decreased. The flame slowed and then shrank back in size. After 9 minutes of burning, the flame self-extinguished when it could not release sufficient chemical energy to overcome the ongoing radiative loss.

Other microgravity experiments of flame spread over thermally thick fuels have been conducted in sounding rockets. In the experiments of Tarifa (1999), they varied the flow rate during each experiment. Ignition took place in a quiescent $40 \% \mathrm{O}_{2}, 1$ atm environment, and after ignition there was no apparent flame visible to the imaging systems. However, when the flow was initiated at a velocity of only $0.8 \mathrm{~cm} / \mathrm{s}$, a flame suddenly appeared on the imaging systems, revealing that there was an "invisible" flame during the quiescent period that become bright enough to see with the imaging camera. 
Other sounding rocket experimenters (Vietoris et al, 2000) burned PMMA in $40 \% \mathrm{O}_{2}$ while step changing the flow velocities from $15 \mathrm{~cm} / \mathrm{s}$ to $10 \mathrm{~cm} / \mathrm{s}$ to $5 \mathrm{~cm} / \mathrm{s}$ flow within one test. While flame spread was observed at the higher flow rates, the flame stopped spreading at $5 \mathrm{~cm} / \mathrm{s}$ and continued to burn in depth for the rest of the test. Conclusions were that the reductions in net heat flux to the surface reductions with flow caused the flame to slow and eventually stop.

The objectives of the sounding rocket experiment reported herein (a.k.a. DARTFire "Diffusive and Radiative Transport in Fires", shown launching in Fig. 1 and schematically in Fig. 2) are to quantitatively determine the effect of low velocity flow, oxidizer concentration, and external radiant heat flux on flame spread over thermally-thick samples. The low velocity flow variable is important because thin fuel work showed (Olson et al., 1988) that even very weak ventilation has a dramatic effect on material flammability and flame spread rate. Oxygen concentration also significantly affects flame spread and flammability. Microgravity flames are weak due to diminished oxygen flow (compared to flames on Earth), and thus more sensitive to heat loss. A variable external radiant flux, envisioned to allow the net heat loss to be varied, is implemented in this experiment for the first time in microgravity.

\section{Experiment}

Two mirror image flow tunnels provide $1-10 \mathrm{~cm} / \mathrm{s}$ flow through each $10 \mathrm{~cm}$ x $10 \mathrm{~cm}$ cross section x $15 \mathrm{~cm}$ long tunnel. Black PMMA samples, $20 \mathrm{~mm}$ long x $20 \mathrm{~mm}$ thick x 6.35 $\mathrm{mm}$ wide, are mounted in the floor of the duct $4 \mathrm{~cm}$ from the inlet flow straighteners and insulated from the aluminum floor using $\sim 0.7 \mathrm{~mm}$ thick fiberfrax insulation, as shown in Fig. 3, which shows a burned sample with instrumentation and igniter wires. The bulk flow speed is controlled by setting the pressure upstream of a critical flow orifice. The gases flow through the test section, and the velocity profile across the duct was measured with a hot wire at $5,10,15$ and 
$20 \mathrm{~cm} / \mathrm{s}$ to verify uniform smooth flow. Pressure in the duct was maintained at 1 atmosphere.

The exhaust gas was vented to the vacuum of space through two opposing jets at the center of gravity of the rocket.

A near-infrared laser diode $(812 \mathrm{~nm})$ and associated custom lenses are mounted in the ceiling of one of the two ducts to provide a uniform external radiant flux of up to $2 \mathrm{~W} / \mathrm{cm}^{2}$ onto the sample surface. The irradiation over the sample is uniform to within $5 \%$. The oval beam covered the entire sample surface and some adjacent sample holder. The controlled external radiant flux allows the surface energy balance to be adjusted to compensate for radiant loss from the surface and gaseous species. The walls of the tunnels have windows for ultraviolet-visible and infrared imaging of the flame. The diode wavelength was selected so that it did not interfere with these imaging devices. The laser diode flux is assumed not to penetrate in-depth for the black PMMA sample; rather it is assumed to be absorbed only at the surface. To estimate the absorptivity of the sample, the spot radiometer (described below) data were compared with the surface thermocouple data from flight $4 \mathrm{~A}$, which had $1 \mathrm{~W} / \mathrm{cm}^{2}$ flux only (no ignition). The absorptivity was calculated to be 0.8 using Kirchoff's law.

Other diagnostics include a surface-viewing spot radiometer (spectral wavelength range of 8-14 $\mu \mathrm{m}$, well outside the laser diode wavelength) which has a $6 \mathrm{~mm}$ diameter field of view that images an area on the surface. The radiometer was calibrated with a black body, and provides effective black body temperatures of the imaged area. A total of 3 gas-phase type $R$ $0.025 \mathrm{~mm}$ diameter and 5 solid-phase type $\mathrm{K} 0.076 \mathrm{~mm}$ diameter thermocouples record flame temperatures (uncorrected, corrections estimated to be $<50 \mathrm{~K}$ ), near-surface pyrolysis temperatures, and in-depth temperatures from each sample during the experiment. 
An intensified array video camera with a resolution of $0.1 \mathrm{~mm}$ and 5 frames per second is used to image the chemiluminescence of $\mathrm{OH}^{*}$ radical species in the flame from an edge view. This type of camera has increased low-light sensitivity over film (for equal exposure time) and therefore can enable direct visualization of selected radical species by incorporating appropriate filters. The chemiluminescence of $\mathrm{OH}^{*}$ in the reaction zone is imaged through $20 \mathrm{~nm}$ bandwidth $\mathrm{OH}^{*}$ filters centered at $310 \mathrm{~nm}$. The camera utilizes peak mode to avoid saturation of the bright flames against the dark background, and optimizes exposure time for each image independently.

Two experiments are conducted simultaneously during the $\sim 6$ minute microgravity experiment. The automatic sequencing starts the flow, and once the flow is established throughout the flow system, the two igniters ignite the samples simultaneously. In one of the two ducts, the laser diode irradiation starts at the same time as the igniter. The igniters turn off after 5 $\mathrm{s}$, and the laser turns off at a prescribed time (depending on test conditions) and then on again at a later time in order to evaluate the effect of a heat flux change on flame spread.

\section{Experimental Results}

The sounding rocket test matrix is shown in Table 1 . The matrix is built around the base case $1 \mathrm{~B}$ of $1 \mathrm{~cm} / \mathrm{s}$ flow at $50 \% \mathrm{O}_{2}$ with no external radiative flux. During Test $1 \mathrm{~A}$, the sample ignited, but the flame extinguished when the igniter was turned off. During test 4A the sample failed to ignite. Spread rates for each test are given in the last column, as discussed below.

An $\mathrm{OH}^{*}$ radical chemiluminescent image is as shown in Figure 4. The dark notches in the flame are shadows of thermocouple posts. There were 3 posts, at $7 \mathrm{~mm}, 10 \mathrm{~mm}$, and $15 \mathrm{~mm}$. Flame spread rates were measured using the $\mathrm{OH}^{*}$ filtered images, which provided the most 
sensitive measure of the location of the chemiluminescent reaction zone not obscured by soot radiation. Some vapor jetting was observed later in the burns due to bubble rupture at the surface of the PMMA. Small bubbles can be seen marring the surface of the burned sample in Fig. 3. The luminous vapor jet typically only lasted $\sim 0.2$ seconds.

\section{Flow Effects on Spread rates}

Unlike the quiescent experiment (Altenkirch et al., 1998), steady flame spread rates were observed at all three opposed flow velocities tested at $50 \% \mathrm{O}_{2}$, as shown in Figure 5. While the $1 \mathrm{~cm} / \mathrm{s}$ test shows small changes in spread rate around the mean, it is considered steady with the regression $R^{2}=0.996$. The other regressions were $R^{2}=0.998$, only slightly better. The flame propagates the full length of the sample, unlike the quiescent case which did not in at least one instance with a longer sample, but did in two with shorter samples. All quiescent cases showed decelerating spread with time, whereas with flow the spread is very linear.

Figure 6 shows the spread rates obtained for the no flux $50 \%$ and $70 \% \mathrm{O}_{2}$ tests as a function of flow for the DARTFire experiments (circles), as well as higher flow experiments at $50 \% \mathrm{O}_{2}$ obtained on earth (Fernandez-Pello et al., 1981), and computations using a 2-D NavierStokes hydrodynamics model with chemical reaction and a 3D radiation model (Deering, 1998). Flame spread rates show a power-law dependence on flow (solid lines), where the approximate exponent on the flow is 0.5 for the $50 \% \mathrm{O}_{2}$ data, whereas the thermal theory of flame spread over thick fuels (de Ris, 1969) predicts a linear dependence on flow. The square root dependence may be related to the velocity gradient in the boundary layer (Wichman, 1983).

It is interesting that this power-law dependence holds down to the $1 \mathrm{~cm} / \mathrm{s}$ imposed flow studied in these tests. The unsteady, two-dimensional numerical model calculations (Deering, 1998) agree with the experimental data at higher flow rates, but predict a more rapid decline in 
spread rate than the power-law at velocities smaller than $5 \mathrm{~cm} / \mathrm{s}$ (dashed line). Under quiescent microgravity conditions, a similar sample extinguished after 9 minutes without full flame propagation (Altenkirch et al., 1998). Thus flame viability and spread over thermally-thick fuels is sensitive to very low velocity flows, as was found to be the case for thermally-thin fuels (Olson et al, 1988), and plastic rods (Ivanov et al., 1999).

\section{Flow Effects on Flame Temperatures}

Measured flame temperatures $1 \mathrm{~mm}$ above the fuel surface generally increased with increasing flow, as shown in Figure 7. There is only a slight change in peak temperature between $1 \mathrm{~cm} / \mathrm{s}$ and $5 \mathrm{~cm} / \mathrm{s}$, but temperatures rise more significantly by $10 \mathrm{~cm} / \mathrm{s}$ flow. In contrast, the model (Deering, 1998) predicts a large increase in temperature between $1 \mathrm{~cm} / \mathrm{s}$ and $5 \mathrm{~cm} / \mathrm{s}$, and less increase between $5 \mathrm{~cm} / \mathrm{s}$ and $10 \mathrm{~cm} / \mathrm{s}$. At $1 \mathrm{~cm} / \mathrm{s}$, the experimental temperatures are much hotter than computed temperatures ( $>500 \mathrm{~K}$ hotter), as shown in the inset to Figure 7. This trend is consistent with the lower spread rates predicted at flows less than $5 \mathrm{~cm} / \mathrm{s}$ whereas above 5 $\mathrm{cm} / \mathrm{s}$, spread rates compare well. The predicted temperatures show a power law dependence with flow, whereas the experimental temperatures plateau at low velocity flow. Three dimensional oxygen diffusion effects may be very important at the low velocities, where boundary layer theory may not be applicable $\left(\operatorname{Re}_{\mathrm{x}} \approx 30\right)$.

One interesting aspect of Figure 7 is that once the leading edge of the flame is past, the temperatures all plateau out to the same temperature beneath the flame. Thus the flow appears to influence primarily the leading edge region of the flame while the trailing diffusion flame is less affected. Because of the higher temperatures at the leading edge at the higher flow rates, the heat flux at the leading edge increases with increasing flow, resulting in increasing flame spread as shown in Figure 6 above. 


\section{External Radiant Flux Effects on Spread Rate}

The near-infrared laser diode had unanticipated effects on flame spread, as shown in Figure 8, in which position of the flame versus time for each of the three flux cases studied is shown. The range of laser flux levels was selected in this experiment to offset the estimated surface radiative loss at $1 \mathrm{~W} / \mathrm{cm}^{2}$, and offset the estimated surface plus flame radiative loss in the $2 \mathrm{~W} / \mathrm{cm}^{2}$ case. The flow selected to study laser effects was $1 \mathrm{~cm} / \mathrm{s}$, clearly in the diffusive transport flow range (Olson et al., 1988).

As listed in Table 1, there was little change in spread rate from the no flux case to the 1 $\mathrm{W} / \mathrm{cm}^{2}$ flux case, until the laser was deactivated. At deactivation, the flame slowed to well below the no flux case, which indicates that the flame was weakened considerably by the sudden removal of the imposed heat flux. Only at $2 \mathrm{~W} / \mathrm{cm}^{2}$ did the laser actually enhance the flame spread rate. At that flux level, the spread rate was enhanced while the laser was activated, and transitioned to the base case no-flux spread rate when the laser was deactivated.

Figure 9 presents the spread rates as a function of external flux level for the sounding rocket data, similar data obtained aboard parabolic aircraft (Olson and Hegde, 1994) at 10 ${ }^{-2} \mathrm{~g}$ $(\sim 5-10 \mathrm{~cm} / \mathrm{s}$ buoyant flow), and numerical model predictions (Deering, 1998). At low flux levels $\left(\leq 1 \mathrm{~W} / \mathrm{cm}^{2}\right)$, the experiments at both $1 \mathrm{~cm} / \mathrm{s}$ and at the higher buoyant flow on the parabolic aircraft show that the laser does not enhance flame spread as strongly as was expected from the numerical model predictions.

The primary visible effect of the laser is a change in flame standoff distance, as shown in Figure 10. Standoff distance was measured by taking the minimum distance between the leading edge of the flame and the initial surface location using the $\mathrm{OH}^{*}$ images. 
For the no flux case (Fig. 10a), the flame standoff reaches a steady value of about 0.6 $\mathrm{mm}$. It takes 40 seconds to reach this value, but then it is steady within the error of the measurement $( \pm 0.1 \mathrm{~mm})$ for the rest of the spread. For the $1 \mathrm{~W} / \mathrm{cm}^{2}$ case (Fig. 10b), the flame standoff distance is just under $0.9 \mathrm{~mm}$ during irradiation, a $50 \%$ increase in flame standoff distance. The flame surprisingly moves out to about $1.05 \mathrm{~mm}$ after the laser shuts off. It stays there for about 20 seconds before beginning to move back in. The standoff distance approaches the $0.6 \mathrm{~mm}$ of the no flux case when the laser turns back on. The flame moves out again after a lag of about 10 seconds. The lag in response attributed to the inertia of the solid phase, as will be shown with the radiometer data.

For the $2 \mathrm{~W} / \mathrm{cm}^{2}$ case (Fig. 10c), the flame standoff distance also varied with flux. The flame standoff distance rises rapidly to about $0.95 \mathrm{~mm}$ (only slightly farther out than the $1 \mathrm{~W} / \mathrm{cm}^{2}$ case), during the laser on. When the laser shuts off, the standoff distance falls back down to 0.6 $\mathrm{mm}$ and stabilizes there while the laser is off. Spread is over before the laser activates again, but when the laser turns on again, standoff distance rises back up.

The flame standoff distance is directly proportional to the conductive heat feadback from the flame to the surface. The flame responds to the laser by adjusting the standoff distance, which reduces or even eliminates the heat flux gain by the laser. Thus the effect of an external heat flux on these flames is not a straightforward augmentation.

\section{External Radiant Flux Effects on Flame Temperatures}

The measured gas-phase temperatures at $1 \mathrm{~mm}$ above the fuel surface during flame passage for different radiant flux levels are shown in Figure 11. The peak temperatures decrease with increasing flux, as shown in the insert to Fig. 11, consistent with the flame standoff distance trends discussed above. In addition, the plateau temperatures remain lower at higher flux during 
and for an extended time after the flux is deactivated (off). This indicates that the effect of the laser persists long after the laser is deactivated. The timescales for this effect are consistent with solid-phase timescales, which indicate, not-unexpectedly, that preheating the fuel enhances flame spread.

\section{Radiant Heat Flux Effects on Radiant Loss}

The laser flux only slightly affects the effective black body fuel surface temperature read by the radiometers, as shown in Figure 12. The radiometer is filtered to transmit only 8-14 $\mu \mathrm{m}$, while the laser is at $810 \mathrm{~nm}$ - well outside the radiometer band, so changes in signal are not due to direct reflection of the laser diode. The temperature drops very gradually when the laser is turned off, which is indicative of the slow coupled gas-solid phase response to the change. The temperature rises quickly when the laser is re-activated, but decays again gradually as the flame increases its standoff distance. Only the $2 \mathrm{~W} / \mathrm{cm}^{2}$ case has a fairly constant temperature beneath the flame. The change in black body temperature is quite small - less than $0.1 \mathrm{~W} / \mathrm{cm}^{2}$, as is shown in the inset to Fig.12, so surface heat loss per unit area beneath the flame can be considered to be approximately constant. Very late in the test, the differences in loss are directly attributable to changes in flame length (where the flame no longer covers the radiometer), as discussed in the next section.

\section{Flame Length Variations with Flow and Flux}

Flame lengths were measured using the $\mathrm{OH}^{*}$ filtered intensified images. The positions of the leading edge (shown previously to determine spread rates) and trailing edge were measured as a function of time, and the difference is plotted below as flame length as a function of time.

As shown in Figure 13, the faster flame spread at higher opposed flow results in a more 
rapid increase to a maximum flame length at the completion of flame spread. At that point, the flame is covering most of the $20 \mathrm{~mm}$ long fuel surface. As steady burning (Emmons-type flame) continues, the overall visible flame length decreases with time in a nearly linear fashion regardless of flow velocity until the visible flame is quite small ( $2-3 \mathrm{~mm}$ in length). The flame does not self extinguish in the time allowed in the test ( $\sim 6$ minutes). In a quiescent environment (Altenkirch et al, 1998), a similar fuel sample did not propagate fully, and self-extinguished in just under 9 minutes. The sample regression below the floor of the duct (reductions in effective opposed flow) and corresponding increasing heat losses to the side walls of the sample holder are believed to be the cause of the flame shrinkage with time, and may result in flame extinction of the Emmons-type flame later on.

The flame length for the flux tests is shown in Figure 14. Early in the tests, the flame growth is driven by the flame spread rate. When the laser turns off, the flames slow their growth rates and then increase them again when the laser turns on as was reflected earlier in the flame spread rates. The effect of imposed flux on flame length is most obvious after maximum flame spread. The laser allows the flame to shrink less rapidly than the no flux case because it is providing heat flux to the surface that helps offset the increasing side-wall losses to the holder.

\section{Mass Loss, Regression, and Burning Rate Trends}

Mass loss was measured by weighing the sample before and after the flight, with the data given in Table 2. The sample was also inspected after the flight to determine the regression profile for each test. The centerline regression profiles are plotted in Figures 15 and 16 as a function of flow and flux. The dimple at $\sim 10 \mathrm{~mm}$ is due to a large sub-surface thermocouple. The centerline had the most significant regression, with less regression toward the side walls.

As shown in Figure 15, the higher the opposed flow rate, the deeper the regression depth 
for the stabilized flame. The leading edge of the stable flame is the anchoring point, so the heat flux in this region is highest and the regression is deepest here. Because standoff distances are less than $1 \mathrm{~mm}$, the fuel regression moves the flame beneath the floor of the test section after approximately one minute of burning beneath the leading edge. In the trailing flame region, the depth shows a similar trend, but the regression depth is much shallower due to the reduced heat flux from the trailing flame.

While the imposed flux did not result in higher regression depths, as shown in Figure 16, it did result in a broader region of regression, especially in the $2 \mathrm{~W} / \mathrm{cm}^{2}$ case, in agreement with the measured longer flame lengths in that case.

Maximum burning rates are estimated in Table 2 from the maximum regression depths, the fuel density, and the total burn time. These estimates, which attempt to capture the local average burning rate at the stabilization point (leading edge) of the flame, are plotted in Figure 17. The maximum burning rate is most sensitive to the opposed flow velocity where a linear dependence on maximum burning rate with flow is found. The laser, on the other hand, has very little effect on the maximum burning rate. This is due to the flame standoff increase with increasing flux, which reduces the conductive flux from the flame. The maximum burning rate thus does not change significantly with laser flux.

The maximum burning rate estimated in this way provides a much better correlation than an average burning rate based on the total mass loss, sample area and total burn time. This is because the flame did not cover the entire sample for the entire time, and heat losses to the walls are significant, so burning rates across the sample surface are not uniform even when flame coverage is complete. 


\section{Net Heat Flux Analysis}

To interpret the unexpected flame response to external heat flux, it is important to take into consideration the energy balance at the fuel surface. The net heat flux to the surface during flame spread was estimated for each $1 \mathrm{~cm} / \mathrm{s}$ test using Equation 1, which includes conduction from the flame to the surface, absorbed external radiative flux from the laser diode, and radiative loss from the surface. It does not include radiative feedback from the flame to the surface.

$$
\text { Net Heat Flux }=k \frac{d T_{g}}{d y} I_{+0}+\alpha q_{e x t}^{\prime \prime}-\varepsilon \sigma\left(T_{s}^{4}-T_{\infty}^{4}\right) \quad \operatorname{Eqn}(1)
$$

This net heat flux then goes into heating up and vaporizing the fuel as the flame spreads, as well as being conductively lost to the sample holder and in-depth fuel. The conduction from the gas to the surface is calculated using $1 \mathrm{~mm}$ gas phase thermocouple data from Figure 11 and assuming that the gas-phase is elliptic at the leading edge so that $\mathrm{dx}$ and dy can be interchanged. The surface radiative loss is calculated using the radiometer black body temperature data (so $\varepsilon=1$ in Eqn (1)). The net heat flux, calculated using Eqn (1), is shown in Table 3. Estimated data for the laser OFF portion of the two flux tests are also included.

The last two columns of Table 3 compare net heat flux to flame spread rate. These values are plotted in Figure 18. While the data are sparse due to the limited number of tests, there is a clear trend of increasing spread rate with increasing net heat flux. The flame response to the laser off condition is shown with the arrows, moving from a higher spread rate-net flux condition to a lower set in each case. The $1 \mathrm{~W} / \mathrm{cm}^{2}$ case after the laser is turned off approaches the quench limit (Altenkirch et al., 1998) when it moves slightly further from the surface and decreases its 
conductive heat transfer as well. The stronger flux flame responded smoothly back to the base no flux condition at the cutoff in laser flux. This indicates that near-limit flames are much more sensitive to sudden changes in surface energy balance, and have a more difficult time adjusting to the changes.

Another way to look at the surface heat flux terms is in ratios. Plotted in the inset to Figure 18 is a ratio of surface radiative loss to the combined gas-phase conductive flux plus external radiant flux. As these relative heat loss becomes greater, the flame spread rate slows down. Eventually, the flame will quench. Additional losses, such as conductive losses to the fuel bed and holder can be comparable to the surface radiative losses (Olson and T'ien, 2000), so the total relative losses can exceed $80 \%$ at extinction.

We can compare the importance of the 3 terms in the net flux equation (1). As shown in Figure 19, the surface loss is nearly constant, and cancels a portion of the gas-phase conduction. The laser flux contributes to the net flux, but because the flame responds to the laser by moving away from the surface, the net heat flux is considerably less than a simple arithmetic addition of the no flux conduction and the laser flux. Thus the predominant factor in flame spread rate reduction is the reduction in heat flux to the surface (conductive and external radiative flux) (Vietoris et al., 2000, Olson and T'ien, 2000) rather than the heat losses themselves, which remain nearly constant.

\section{$\underline{\text { Discussion }}$}

The importance of three dimensional effects on flame spread should be considered in the comparison of the experiment with the numerical predictions. While the model does incorporate $3 \mathrm{D}$ radiation, the model hydrodynamics are two-dimensional. As found for thermally-thin fuels (Mell and Kashiwagi, 1998) the effect of oxygen side diffusion into the flame zone is equivalent 
to increasing the flow speed for the $2 \mathrm{D}$ case, which makes the flame stronger. Thus it is not surprising that at very low speed flows, on the order of diffusive velocities, that the $2 \mathrm{D}$ model under-predicts the flame spread rate for this inherently 3D experiment.

The experiment is inherently three dimensional, as evidenced in the solid phase by the regression history of each sample, and as evidenced in the gas phase by parabolic aircraft experiments conducted to determine the sample size for the flight experiment. Figure 20 a) and b) shows a sequence of images taken from an aircraft test with a $2 \mathrm{~cm}$ wide sample and the 0.635 $\mathrm{cm}$ wide sample that DARTFire used. While the $0.635 \mathrm{~cm}$ sample show a convex flame front, the wider sample had a concave flame front throughout the trajectory, with the edges of the sample showing enhanced flame spread relative to the center of the fuel. This result was consistent throughout the width effect test series with two different insulation materials and various widths - the non-uniformity got progressively worse as the sample was widened from $0.635 \mathrm{~cm}$ to $2 \mathrm{~cm}$. The non-uniform flame front may be due to near-limit phenomena or instabilities similar to those reported by Prasad et al.(2002) or Zik (1998). Because DARTFire was focused on thermally-thick flame spread and not flame front instabilities, we chose the 0.635 $\mathrm{cm}$ wide sample for consistency with the previous tests (Altenkirch, 1998), and to eliminate the non-uniformity in the flame front as it spread.

Another possible contributing factor to consider to explain the increased spread rates at low velocity flow is residual gravity during the test. Even a very slight body force due to spin or drag on the rocket over those predicted from the model may be sufficient to generate a weak buoyant flow. The recorded residual gravity level during the experiment was less than the accelerometer detection threshhold of $4 \times 10^{-4} \mathrm{~g}$. As shown in Fig.21, just prior to a late extinguishment in the first launch, the deceleration upon reentry felt by the flame increased to 
$7 \times 10^{-3} \mathrm{~g}$ before discernable effects on the flame were observed. Thus, residual gravity is negligible in these experiments.

One of the more interesting phenomena found in these experiments is the unexpected behavior of flames to low flux levels. "Low" is relative, because $1 \mathrm{~W} / \mathrm{cm}^{2}$ is above the minimum flux needed to radiatively ignite black PMMA (Quintiere, 1981). The DARTFire sample has significantly more heat loss to the surroundings because of its small sample size, and DARTFire test 4A demonstrated that the sample's surface temperature under an imposed flux of $1 \mathrm{~W} / \mathrm{cm}^{2}$ reached a plateau at approximately the glass temperature of PMMA $\left(105^{\circ} \mathrm{C}\right)$, which is much lower than required for ignition. Because of the large heat losses to the holder, the base case of $1 \mathrm{~cm} / \mathrm{s}$ is fairly close to the extinction limit. A larger sample would have significantly less heat loss per unit area, and would likely respond more like the $2 \mathrm{~W} / \mathrm{cm}^{2}$ case - i.e. it would transition more smoothly between conditions.

The transition from the irradiated flame to the non-irradiated flame for the $1 \mathrm{~W} / \mathrm{cm}^{2}$ case started by the flame weakening significantly, and only gradually recovering toward the nonirradiated base case. This suggests that flames in microgravity, especially in the very low velocity diffusive flow regime, are very sensitive to changes in environment, especially when the change weakens the flame. While the two end states might both be viable independently, the path the transition takes toward the weaker state may not connect the two and instead may lead to extinction. This is a topic of significant interest and additional research would help further elucidate the complex interactions between diffusion and radiation.

Lastly, based on the DARTFire data, we can rank the sensitivity of microgravity flame spread over thermally thick fuels to flow, flux, and oxygen concentration. A tenfold increase in flow results in $125 \%$ increase in spread rate, a twofold increase in flux results in $50 \%$ increase in 
spread rate, and a $50 \%$ increase in ambient oxygen concentration results in $100 \%$ increase in spread rate. Clearly, flame spread rate is most sensitive to oxygen concentration. This suggests that spacecraft should limit the operational oxygen concentrations to as low a value as possible, because any increase dramatically increases the fire hazard of materials. Also, it is unlikely that

perfect quiescence is feasible in an inhabited, powered space vehicle where air flows are typically higher than $5 \mathrm{~cm} / \mathrm{s}$ due to crew motions, ventilation, and cooling systems, so the quiescent extinction condition may not be realized in practice. These all have implications for spacecraft and extraterrestrial fire safety.

\section{Conclusions}

The DARTFire sounding rocket experiment series provides a wealth of new information on opposed flow flame spread over thermally-thick solids under differing low velocity opposed flows and external radiant flux levels.

The effect of flow velocity on flame spread over the $1-10 \mathrm{~cm} / \mathrm{s}$ range extends data previously reported at high opposed flows almost two decades lower in flow. Steadily propagating flames in opposed flow are found down to $1 \mathrm{~cm} / \mathrm{s}$ flow, even though previous experiments showed that quiescent conditions do not support steady flame spread. This demonstrates that even a flow on the order of diffusive velocities $\left(0^{+}\right.$to $\left.2 \mathrm{~cm} / \mathrm{s}\right)$ is sufficient to sustain combustion where in a perfectly quiescent environment, the flame would not be viable.

The flame spread rate showed a surprising insensitivity to imposed flux levels that roughly compensates for the surface radiative loss $\left(1 \mathrm{~W} / \mathrm{cm}^{2}\right)$. The flame standoff distance increased with an imposed flux, and the conductive feedback from the flame was reduced, apparently compensating for the imposed radiative flux. At $2 \mathrm{~W} / \mathrm{cm}^{2}$, however, despite an even larger standoff distance, the flame spread rate increased. This non-linear trend with imposed 
radiation was not predicted by the detailed numerical models developed by the investigator team. However, estimates of the net heat flux to the surface do correlate with spread rate, which indicates that the net flux (conduction plus imposed radiation minus surface radiative loss) to the surface is what drives the flame spread rate.

Flame length did not remain steady during the tests, and the flames shrank to very small size later in the tests. The trailing edge motion was very sensitive to heat losses, as demonstrated by the longer flames with the added heat flux from the laser diode. While extinction was not observed, the regression of the sample caused the flame to weaken as it sank below the floor of the flow duct, where the effective flow velocity decreased and heat losses to the sample walls increased.

Flame spread rate is more sensitive to oxygen concentration than flow or external radiant flux. This has spacecraft and extraterrestrial fire safety implications; it suggests that spacecraft should limit the operational oxygen concentrations to as low a value as possible, because any increase dramatically increases the fire hazard of materials.

Acknowledgments: This work was funded under NASA Cooperative Agreement NCC3-221. The experimental hardware was developed and tested by the DARTFire project team (Jeff Jones, Project Manager), and launched with the support of Wallops Island and White Sands Missile Range personnel. Special thanks to the NASA Glenn Graphics Visualization Lab, who processed the image data. 


\section{References}

Altenkirch,R.A.,Tang,L.,Sacksteder,K.,Bhattacharjee,S.,and Delichastios,M.A.; ( 1998), Proc. Combust. Instit., 27, pp. 2515-2524.

Altenkirch, R. A., Olson, S.L., Deering, J.L., Tang, L., Bhattacharjee, S., and Hedge, U., (1999) proceedings of the Fifth International Microgravity Combustion Workshop, Cleveland, OH, May 18-20.

Deering, J.L., MS Thesis, Washington State University, Dec. 1998.

de Ris,J.N.,Proc. Comb. Inst., V.12, pp.241-252, 1969.

Fernandez-Pello, A.C., Ray, S., and Glassman, I.; (1981) Proc. Combust. Instit., 18, pp. 579-589.

Ivanov,A.V.,Balashov,Ye.V,Andreeva,T.V,and Melikhov, A.S.; (1999), NASA CR-1999209405.

Mell, W.E. and Kashiwagi, T.; (1998) Proc. Combust. Instit. 27, pp. 2635-2641.

Olson, S.L., Ferkul, P.V., and T’ien, J.S.; (1988), The Proc. Combust. Instit., V.22, pp. 12131222.

Olson, S.L., and Hegde, U., (1994) Eastern States Section Fall Technical Meeting, the Combustion Institute, Clearwater Beach, FL.

Olson, S.L., Altenkirch, R. A., Bhattacharjee, S., Tang, L., Hegde, U., (1997) proceedings of the Fourth International Microgravity Combustion Workshop, Cleveland, $\mathrm{OH}$.

Olson, S.L., and T'ien, J.S.; (2000) "Buoyant Low Stretch Diffusion Flames Beneath Cylindrical PMMA Samples, Combustion and Flame, 121, pp. 439-452.

Prasad, K., Olson, S.L., Nakamura, Y., Fujita, O., Nishizawa, K., Ito, K., and Kashiwagi, T.; (2003), Proc. Combust. Instit., 29, to appear.

Quintiere,J.G., (1981), Fire and Materials 5: 2, pp. 52-60.

Tarifa, (1999), $5^{\text {th }}$ Microgravity Combustion Workshop, NASA/CP-1999-208917, pp. 39-42.

T'ien, J.S., Shih, H-Y., Jiang, C-B., Ross, H.D., Miller, F.J., Fernandez-Pello, A.C., Torero, J.L., and Walther, D.; (2001) Chapter 5 of Microgravity Combustion: Fire in Free Fall, Ross, H.D., (Ed). Academic Press.

Vietoris, T., Ellzey, J.L., Joulain, P., Mehta, S., and Torero, J.L., (2000), Proc.Combust. .Instit., 28, pp. 2883-2889.

Wichman, I.S., (1983) Combustion and Flame 50, pp. 287-304.

Zik, O., and Moses, E., (1998), Proc. Combust., Instit, 27, pp.2815-2820. 


\section{Figure Captions}

Figure 1: DARTFire launch of two stage sounding rocket. Experiment section is insulated in white foam box, which strips away during launch.

Figure 2: Schematic of Research Section of Sounding Rocket for DARTFire. The research section is $2.44 \mathrm{~m}$ long, $0.43 \mathrm{~m}$ in diameter, and weighs $209 \mathrm{~kg}$. The flow supply system comprises the first third of the rocket, while the experimental flow tunnels and diagnostics (cameras, radiometers, laser) are located in the middle third of the rocket. The remaining third houses the electronics and video storage devices. The samples are positioned near the center of gravity of the rocket.

Figure 3: Burned sample showing instrumentation and igniter wires. Maximum regression is $\sim 2$ $\mathrm{mm}$. Surface igniter embedded near one end of the sample vaporizes the fuel, and the loop igniter at the downstream end of the sample ignites the fuel vapors. Sample is embedded in aluminum holder, insulated with fiberfrax insulation around its perimeter. Gas phase thermocouples are at 1,3, and $2 \mathrm{~mm}$ above the sample. Three surface (bare beads) and one subsurface thermocouple (cylindrical bump) are embedded in the solid. Outer side posts are to block glowing thermocouple wires from camera views.

Figure 4: $\mathrm{OH}^{*}$ chemi-luminescent intensified image of flame spreading over black PMMA sample from an edge view image. Flame spread is downward, with dark posts blocking parts of the flame. Vertical scale minor ticks are $0.5 \mathrm{~mm}$ apart; horizontal scale ticks are $1 \mathrm{~mm}$ apart. A vapor jet is shown normal to the tail region of the flame.

Figure 5: Position of the leading edge of the flame measured from the $\mathrm{OH}^{*}$ images as a function of time for tests three opposed flow velocities at $50 \% \mathrm{O}_{2}$. The gaps in the data near 7, 10, and 15 $\mathrm{mm}$ are when the flame is propagating behind a thermocouple post. The linear regressions (lines) shown resulted in spread rates of $0.20 \mathrm{~mm} / \mathrm{s}, 0.32 \mathrm{~mm} / \mathrm{s}$, and $0.45 \mathrm{~mm} / \mathrm{s}$ for 1,5 , and $10 \mathrm{~cm} / \mathrm{s}$ flow.

Figure 6: Comparison of flame spread results from DARTFire tests with higher flow data (Fernandez-Pello et al., 1981) and numerical model predictions (Deering, 1998). Flame spread rates show a power-law dependence on flow (solid line), where the approximate exponent on the flow is 0.5 even down to the unsteady case for the $50 \% \mathrm{O}_{2}$ data. The unsteady, two, dimensional numerical model calculations agree with the experimental data at higher flow rates, but predict a more rapid decline in spread rate than the power-law at velocities smaller than $5 \mathrm{~cm} / \mathrm{s}$ (dashed line). 
Figure 7: Gas-phase temperatures measured during flame passage at $1 \mathrm{~mm}$ above the fuel surface at three flow conditions for $50 \% \mathrm{O}_{2}$. There is only a slight change in peak temperature between 1 $\mathrm{cm} / \mathrm{s}$ and $5 \mathrm{~cm} / \mathrm{s}$, but temperatures rise more significantly by $10 \mathrm{~cm} / \mathrm{s}$ flow. Once the leading edge of the flame is past, the temperatures all plateau out to the same temperature beneath the flame. The inset shows maximum flame temperature as a function of flow compared with theoretical predictions.

Figure 8: Position of the leading edge of the flame from the $\mathrm{OH}^{*}$ image as a function of time for the three flux levels tested at $50 \% \mathrm{O}_{2}$. Spread rates for each portion of the test are given in Table 1.

Figure 9: Spread rate as a function of external flux level for the $1 \mathrm{~cm} / \mathrm{s}$ sounding rocket data(blue), similar data obtained aboard parabolic aircraft (Olson and Hegde)(green) at $10^{-2} \mathrm{~g}(\sim 5-$ $10 \mathrm{~cm} / \mathrm{s}$ buoyant flow), and numerical model predictions(Deering, 1998)(red). At low flux levels $\left(\leq 1 \mathrm{~W} / \mathrm{cm}^{2}\right)$, the experiments at both $1 \mathrm{~cm} / \mathrm{s}$ and at the higher buoyant flow on the aircraft show that the laser does not enhance flame spread as strongly as was expected from the numerical model predictions.

Figure 10: Flame standoff distance measured as a function of time, shown with the laser power data on the right axis: a) no flux; b) $1 \mathrm{~W} / \mathrm{cm}^{2}$; c) $2 \mathrm{~W} / \mathrm{cm}^{2}$.

Figure 11: Gas-phase temperatures measured during flame passage at $1 \mathrm{~mm}$ above the fuel surface at three external radiant flux conditions for $50 \% \mathrm{O}_{2}$. The peak temperatures decrease with increasing flux, consistent with the flame standoff distance trends. Plateau temperatures beneath the flame show a similar trend.

Figure 12: Effective black body temperature of surface emissions as a function of time, based on the radiometer data. The total radiant loss is only slightly affected by the laser after leading edge passage, as shown by the off and on indicators. The slight jump in surface radiative heat loss when the laser is re-activated is shown in the inset. The no flame case shows the surface temperature reaches a constant value of less than $100^{\circ} \mathrm{C}$ for $1 \mathrm{~W} / \mathrm{cm}^{2}$ imposed.

Figure 13: Effect of Flow on Flame Length. After steady spread, the flame stabilizes over the PMMA sample. However, a steady reduction in length with time is noted. While the leading edge gradually moves back a few $\mathrm{mm}$ from the upstream end of the sample, the primary reason the flame length shrinks is because the trailing edge of the flame shortens. 
Figure 14: The effect of laser flux on flame length. Notice the higher flux cases result in a considerably longer flame after full spread has been achieved. The stronger the laser, the larger the difference in flame length. The trailing edge of the flame does not shrink as quickly when the laser is on, indicating the trailing edge motion is very sensitive to heat losses.

Figure 15: Centerline regression profiles as a function of flow. Note scale difference in $\mathrm{x}$ and $\mathrm{y}$ scales.

Figure 16: Centerline regression profiles as a function of flux. Note scale differences between $x$ and y scales.

Figure 17: Maximum burning rate as a function of either flow or flux.

Figure 18: Flame spread rate dependence on net heat flux to the surface, based on values in Table 3. Inset shows spread rate compared with relative heat loss.

Figure 19: Cumulative bar chart showing each term in Eqn (1).

Figure 20: The experiment is inherently three dimensional, as evidenced by these sequences of images from parabolic aircraft experiments conducted to determine the sample size for the flight experiment.

a) The first sequence of 4 images is for a $2 \mathrm{~cm}$ wide sample with well-insulated edges. The images are taken at 5 second intervals, and show flame spread is clearly enhanced along the edges, whereas the center portion of the flame lags behind.

b) For the second sequence, the DARTFire sample is tested - a $0.635 \mathrm{~cm}$ wide sample with a narrow strip of fiberfrax insulation.3. The sample is sufficiently narrow, and heat losses are high so that a bullet-shaped flame front forms.

Figure 21: Near-surface thermocouple reading under the flame during reentry of the sounding rocket, just prior to venting extinction. The RMS acceleration rises from a noise level of $4 \times 10^{-4} \mathrm{~g}$ to over $7 \times 10^{-3} \mathrm{~g}$ before the near-surface thermocouple shows a rise from its stable level of $\sim 500^{\circ} \mathrm{C}$. 


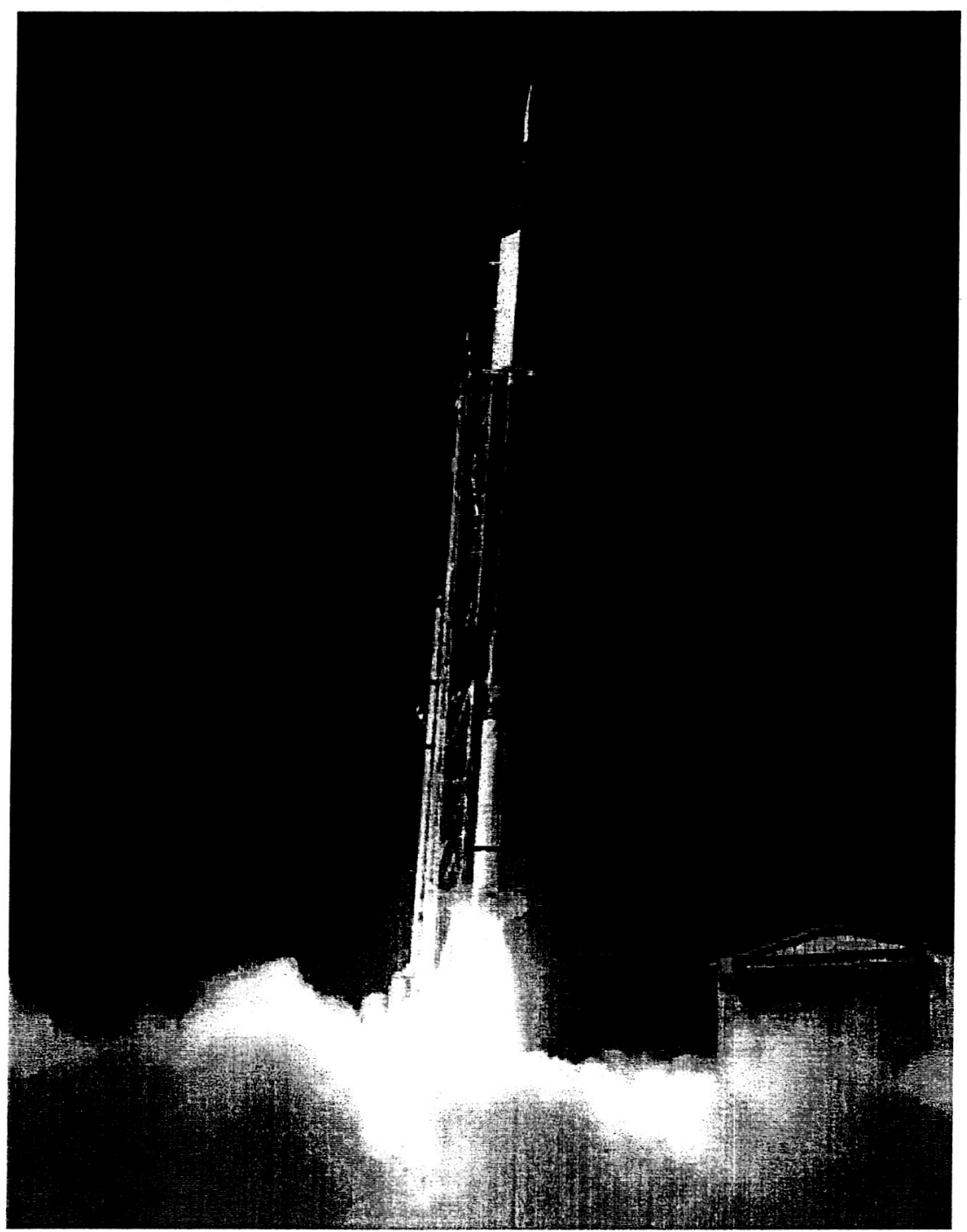

Figure 1 


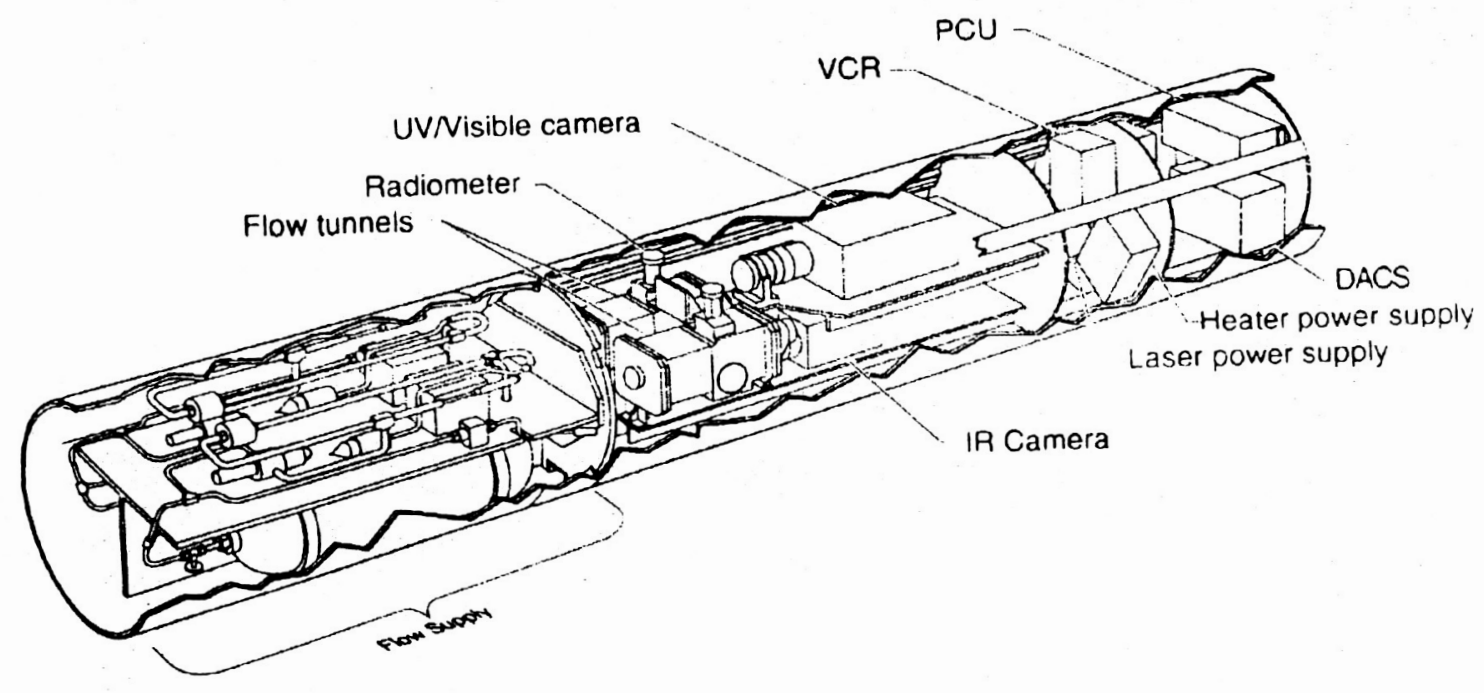

Figure 2 


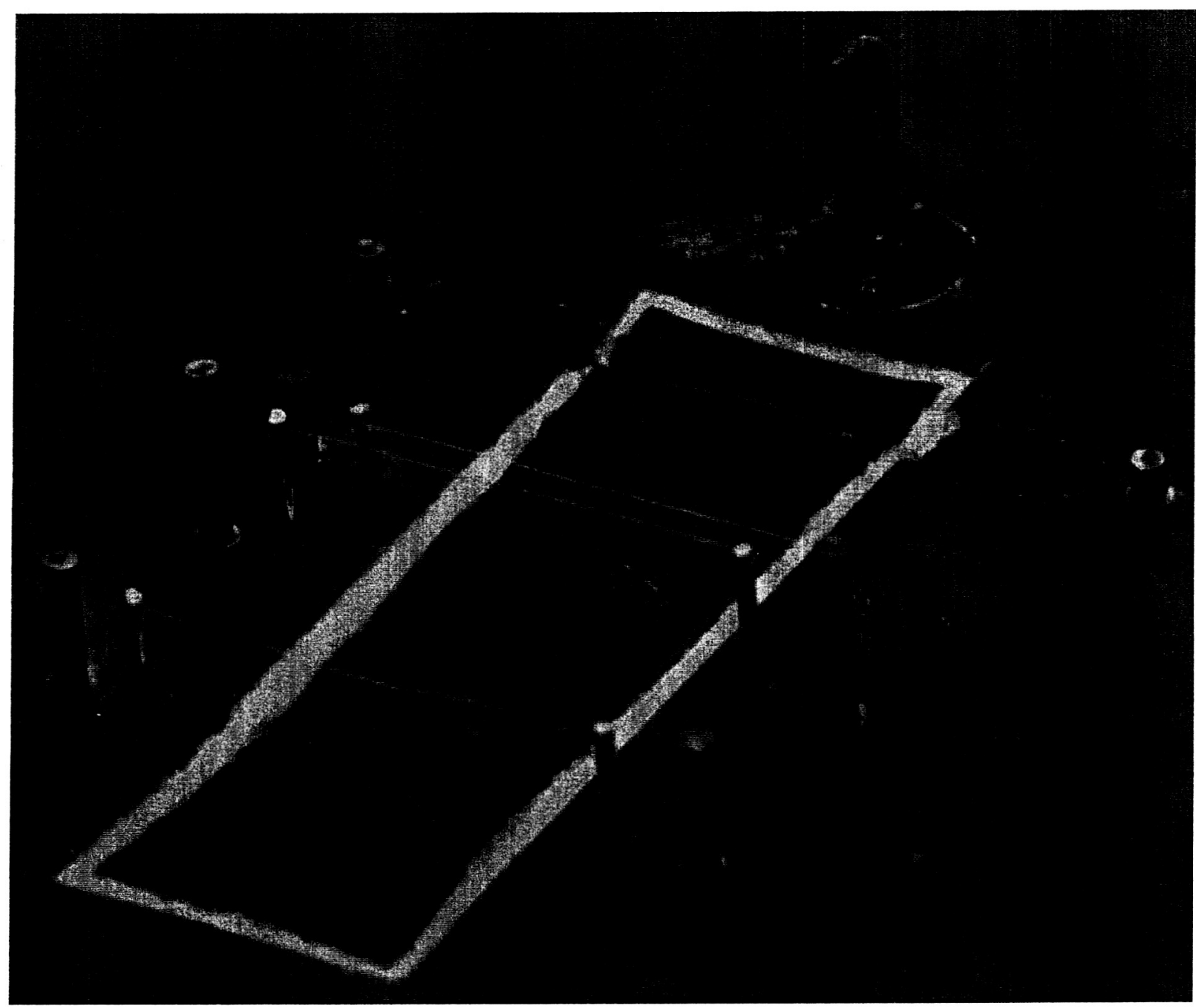

Figure 3 


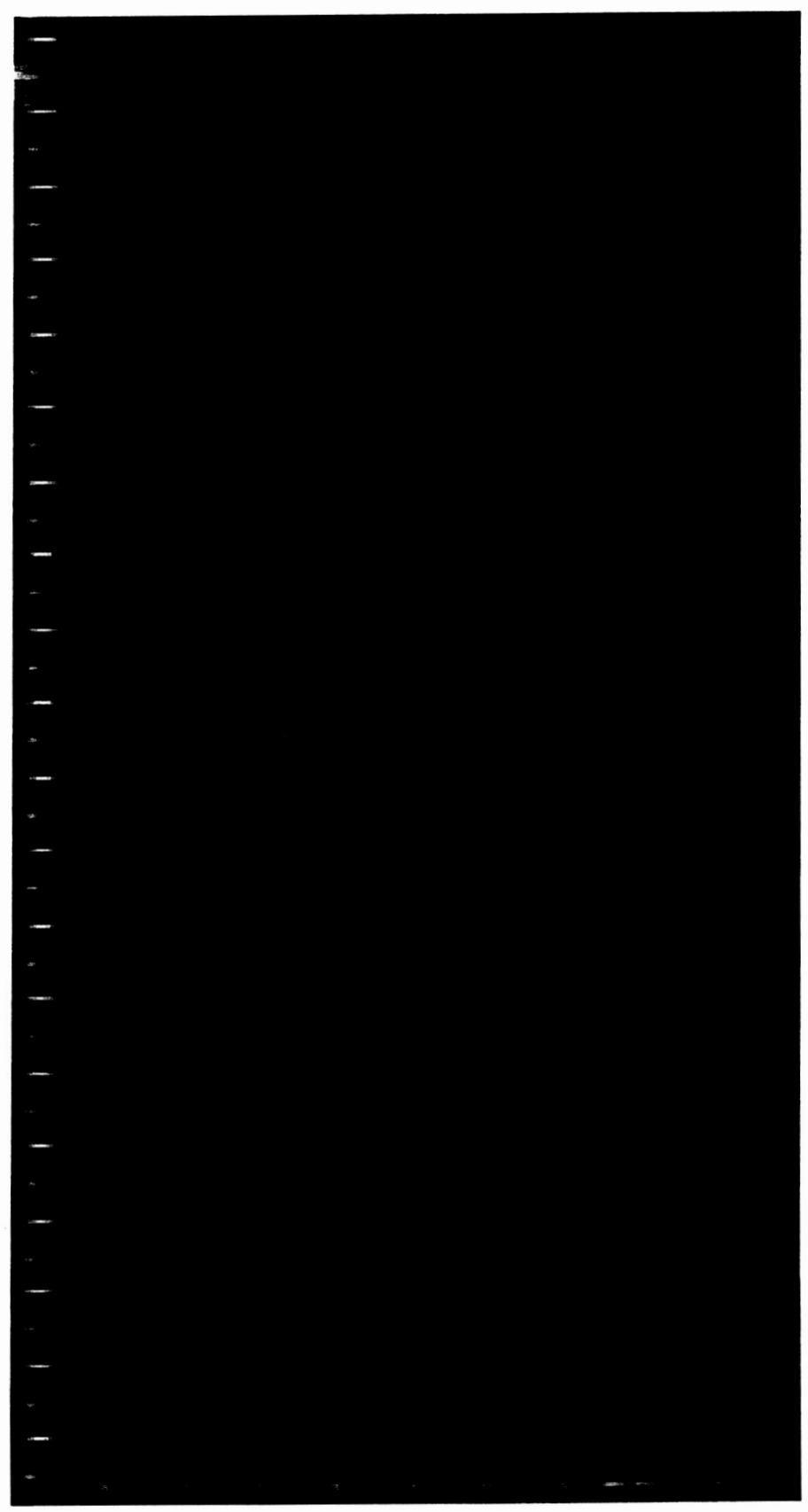

Figure 4 


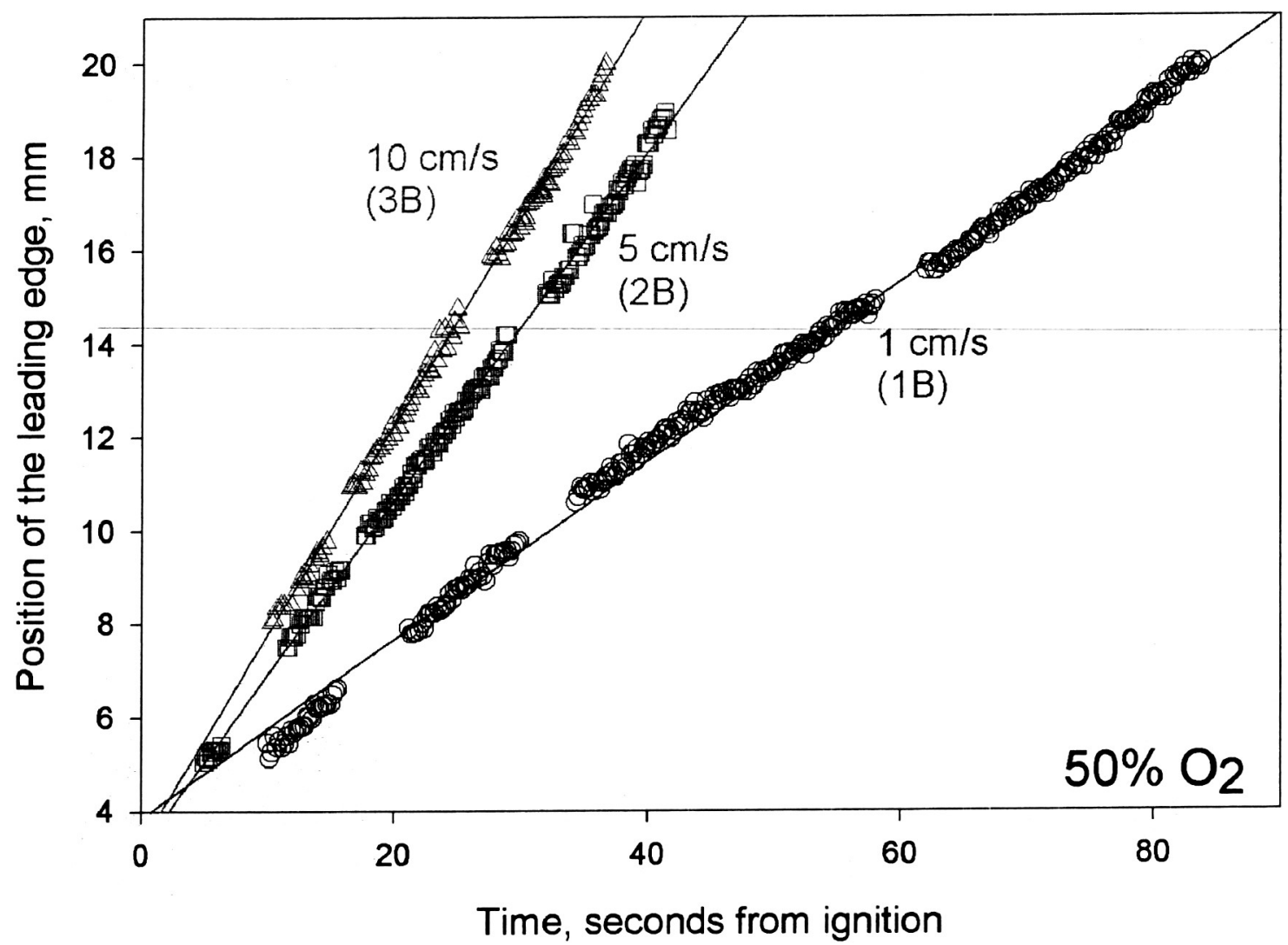

Figure 5 


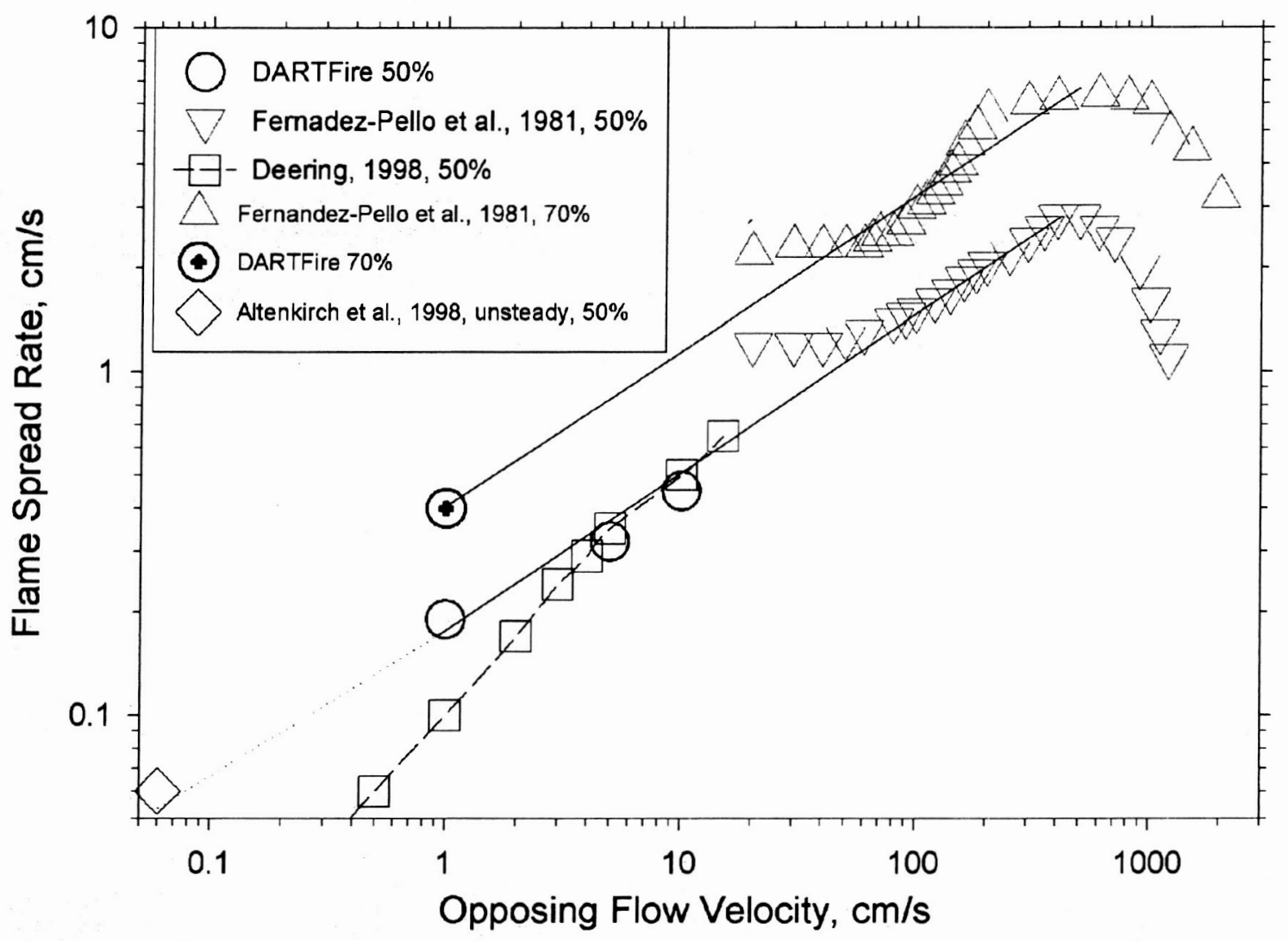

\section{Figure 6}




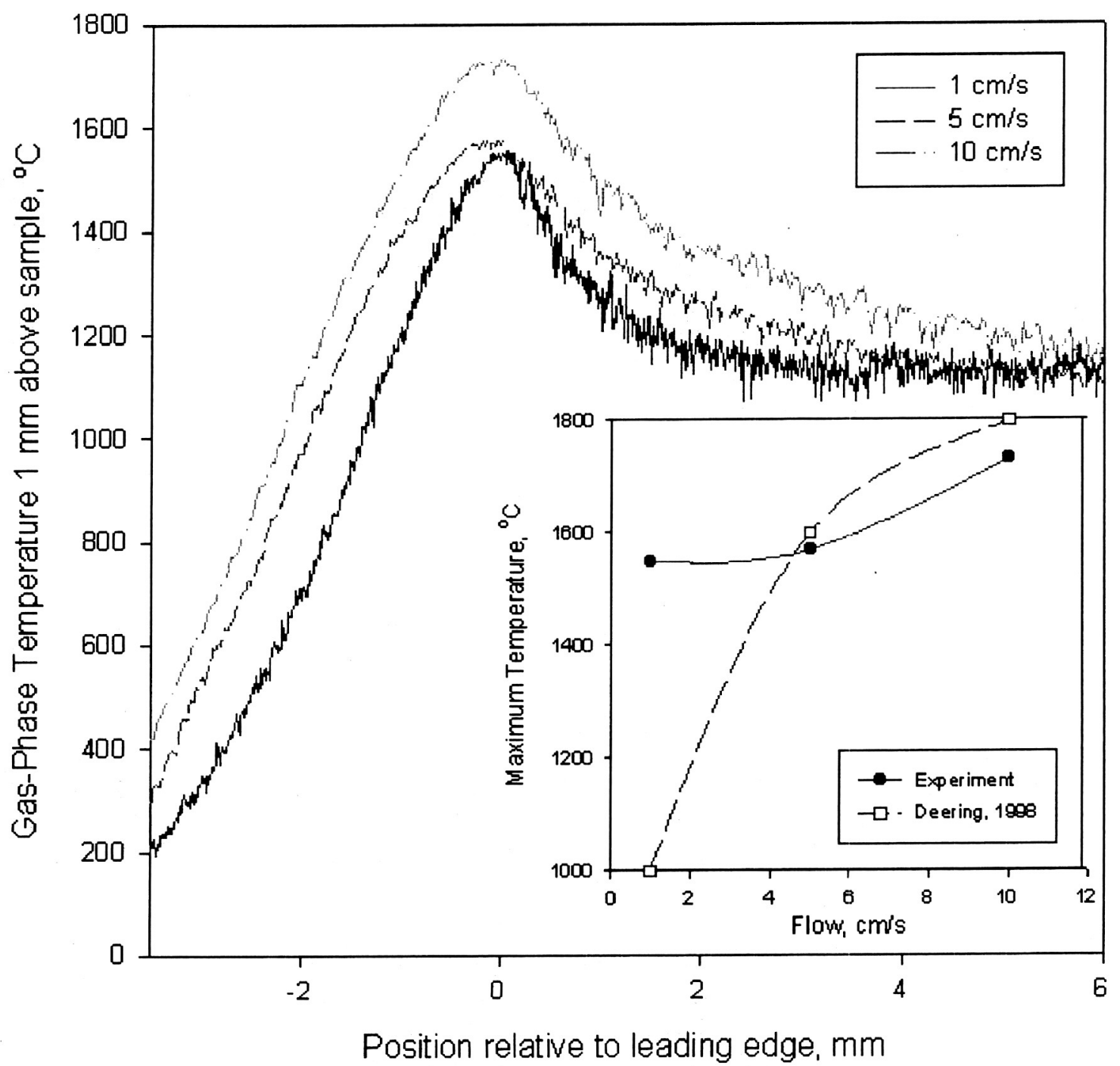

Figure 7 


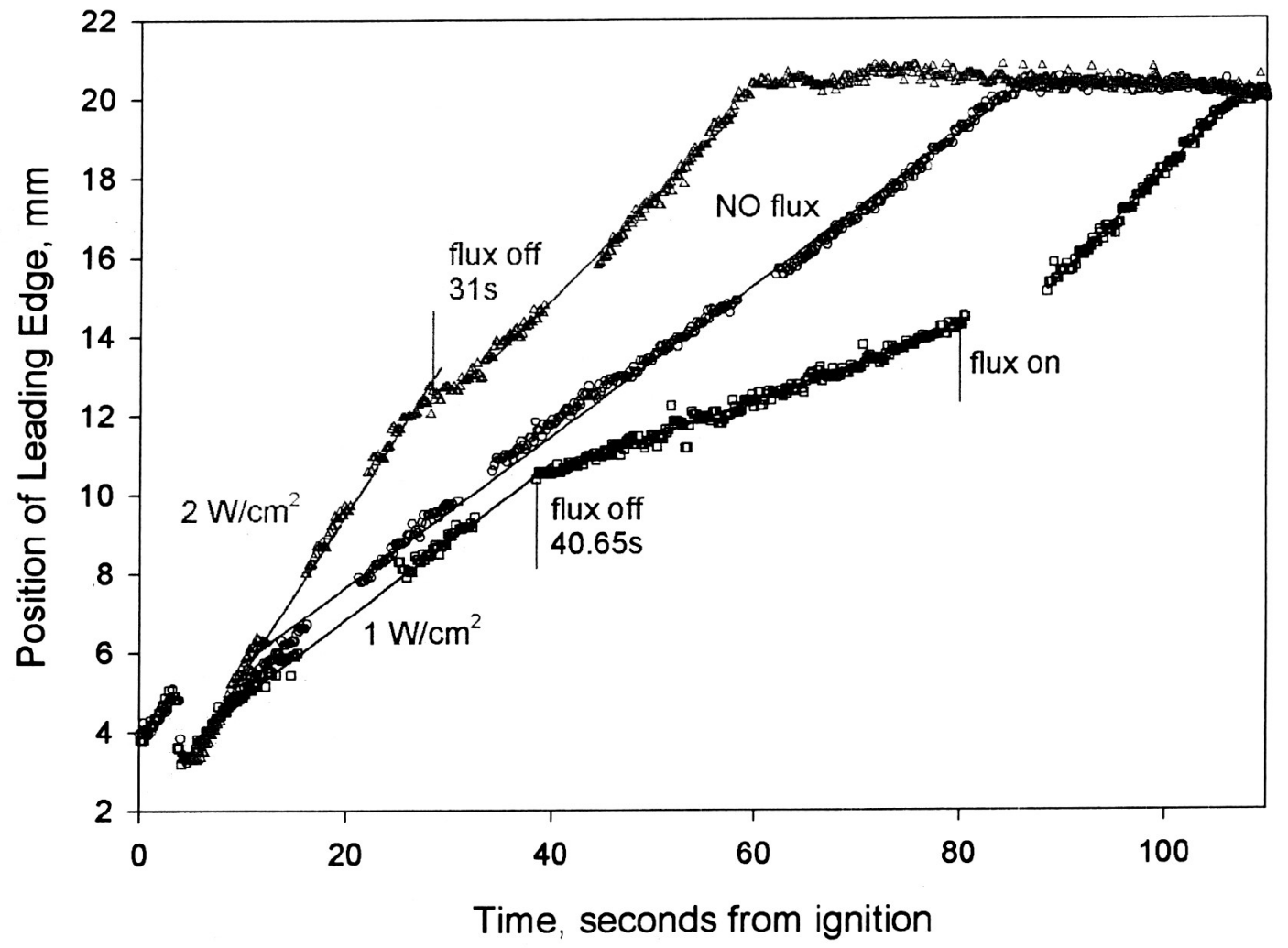

Figure 8 


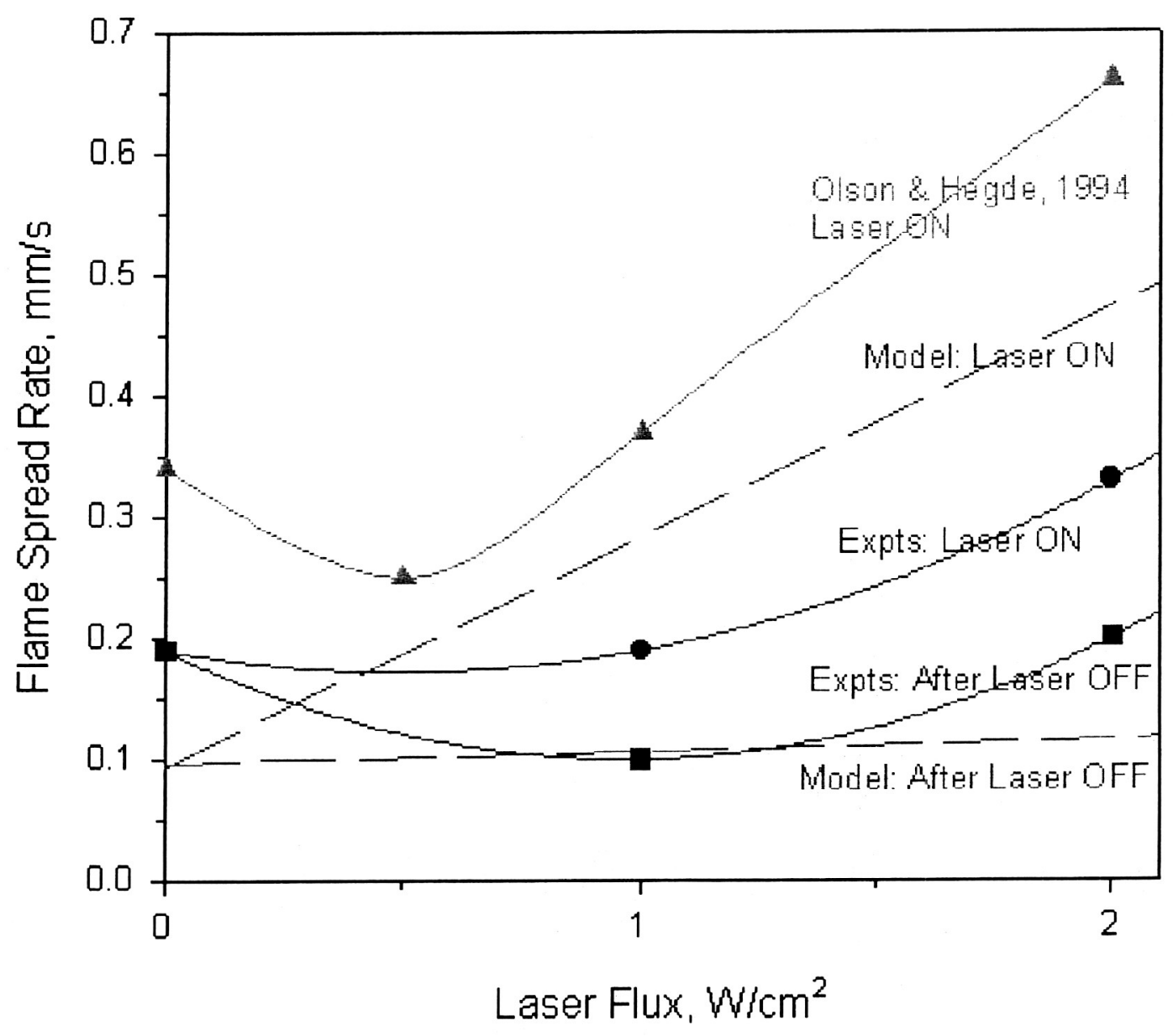

Figure 9 

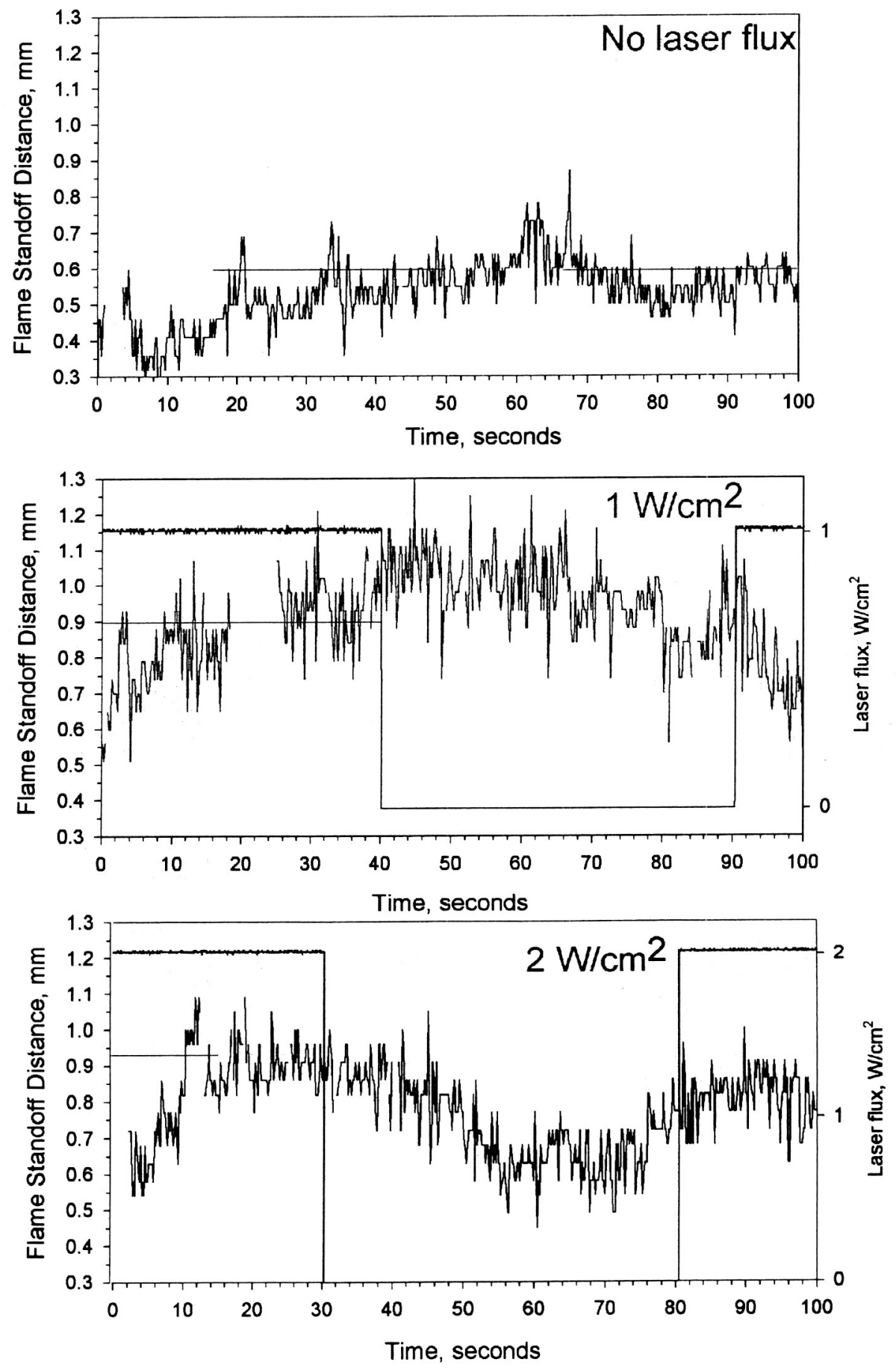

Figure 10 


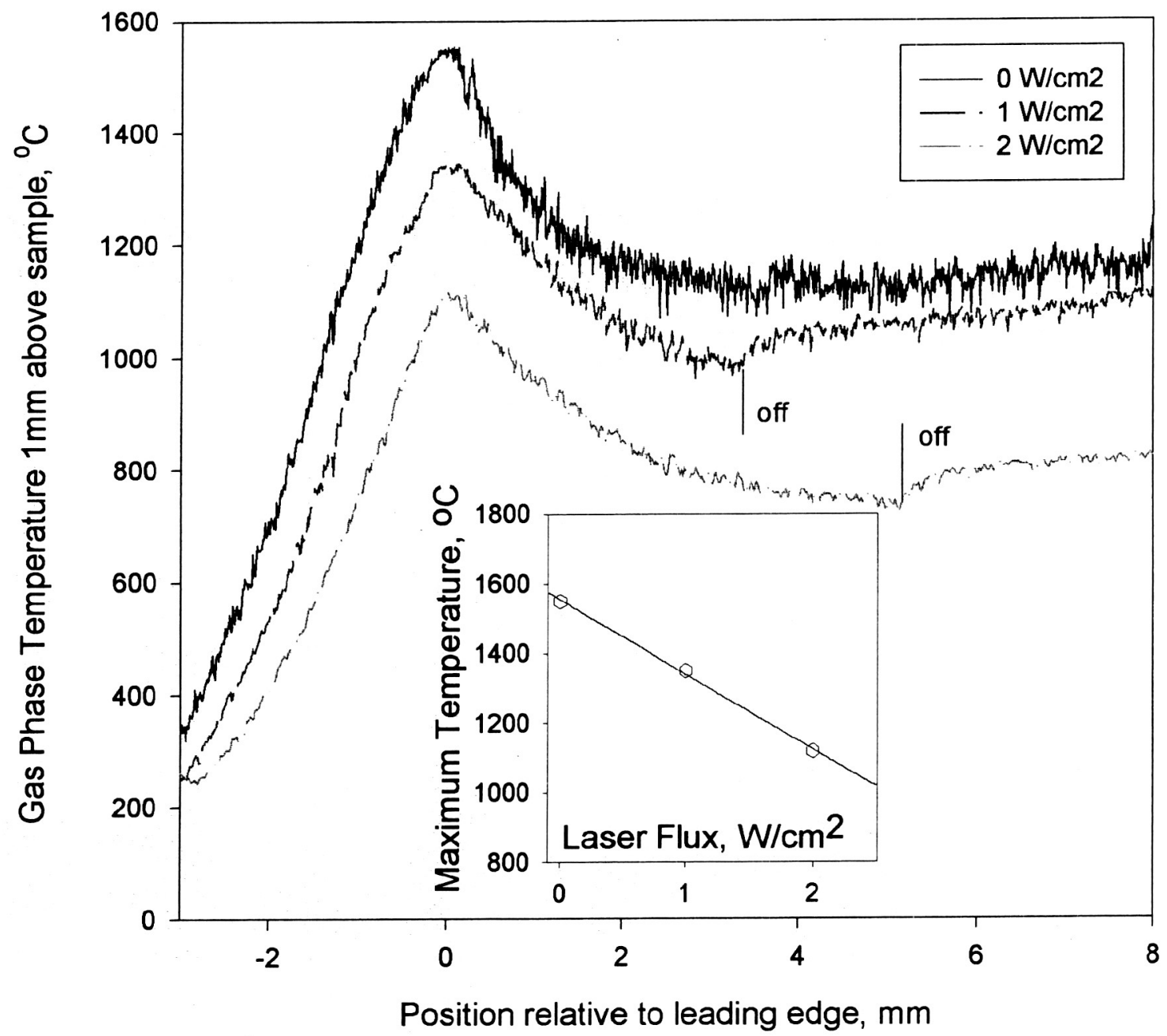

Figure 11 


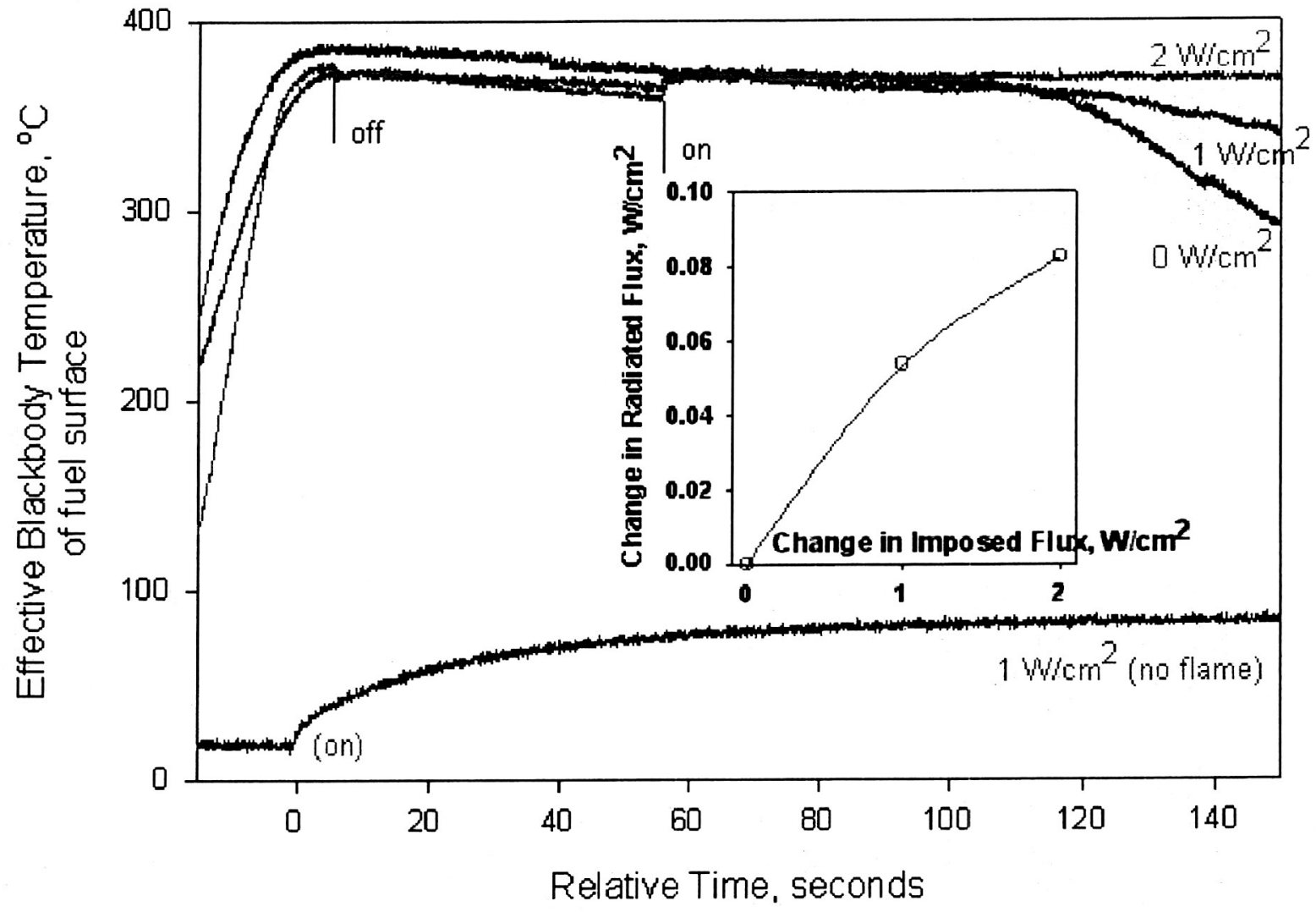

Figure 12 


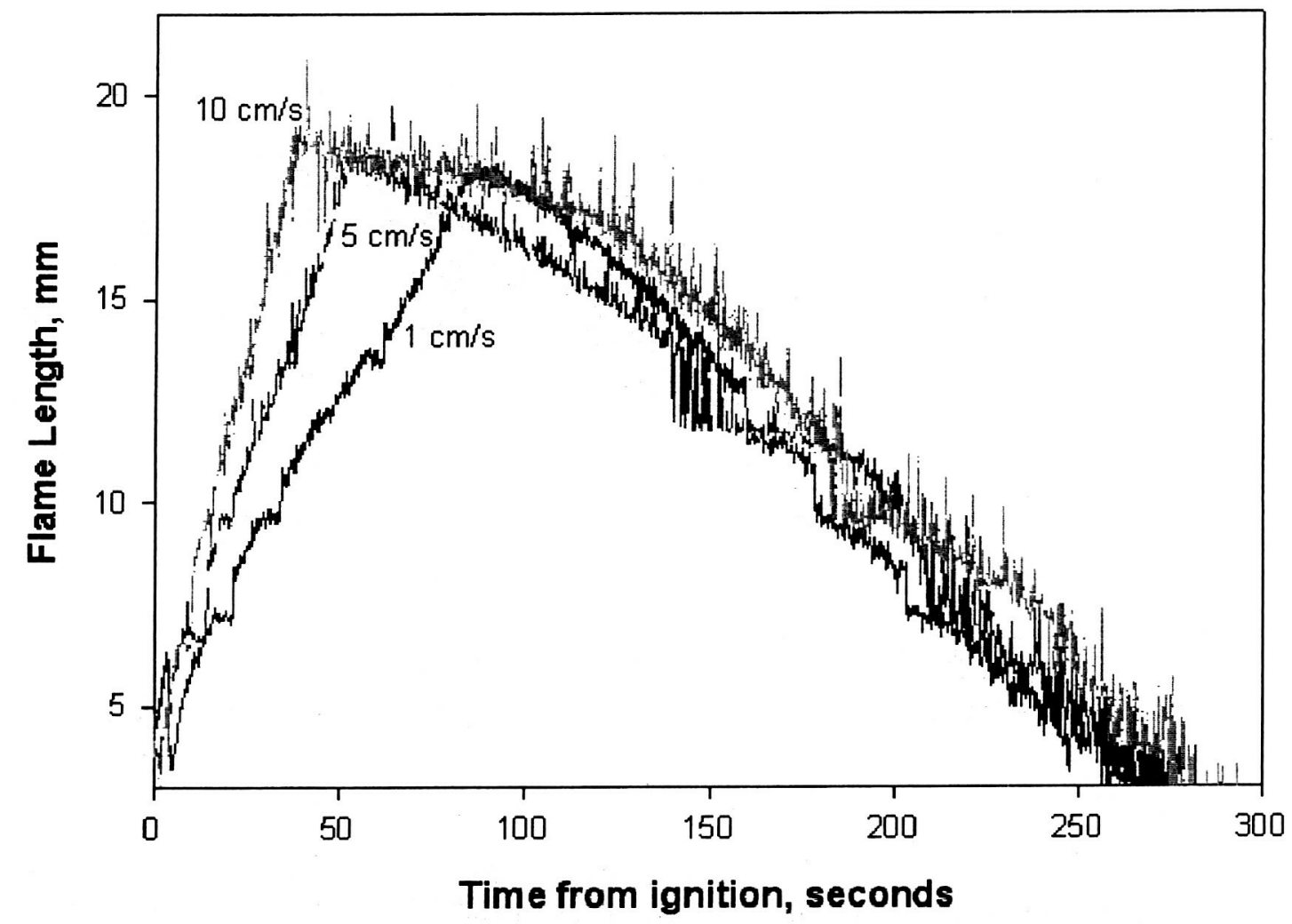

Figure 13 


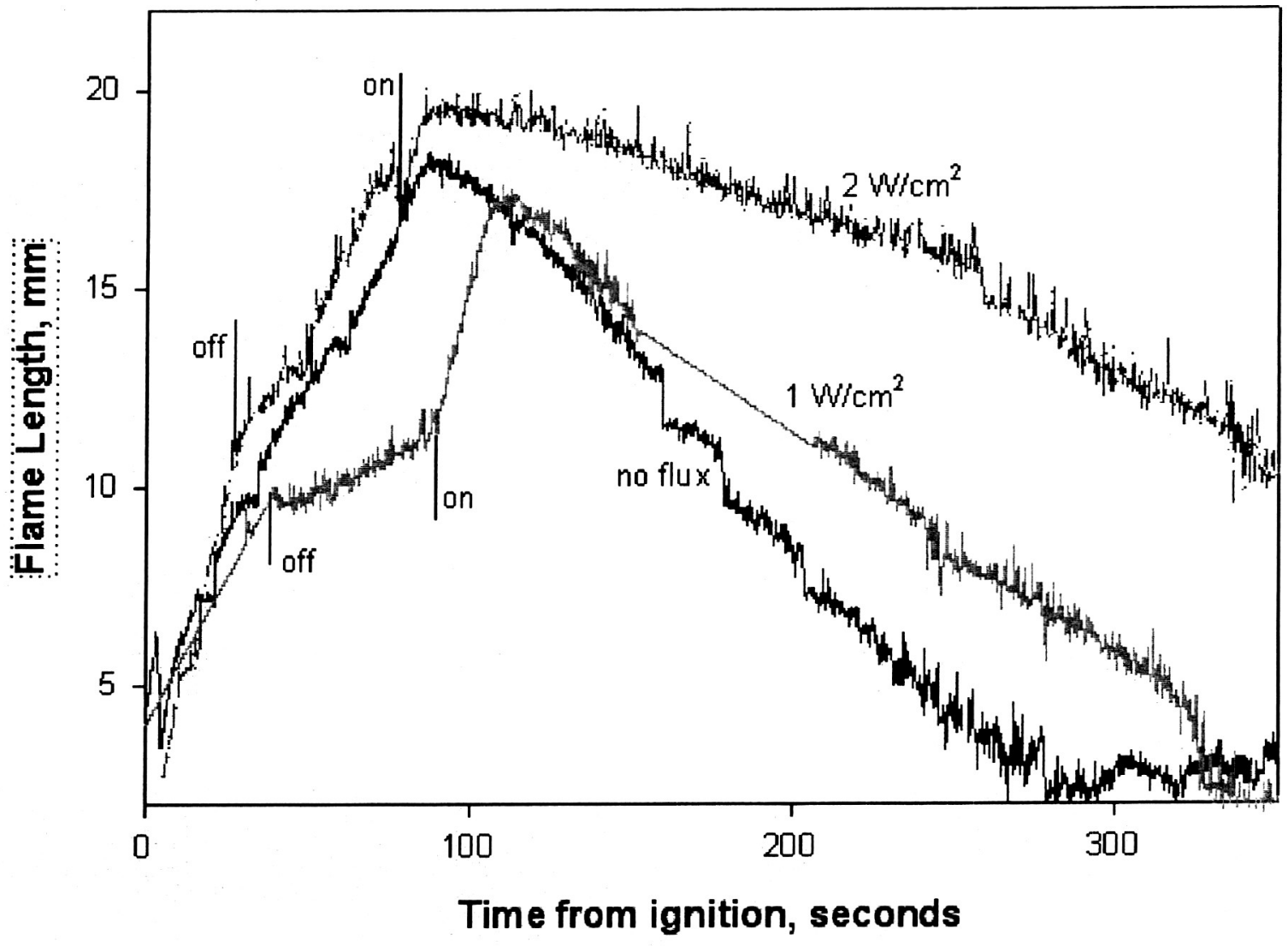

Figure 14 


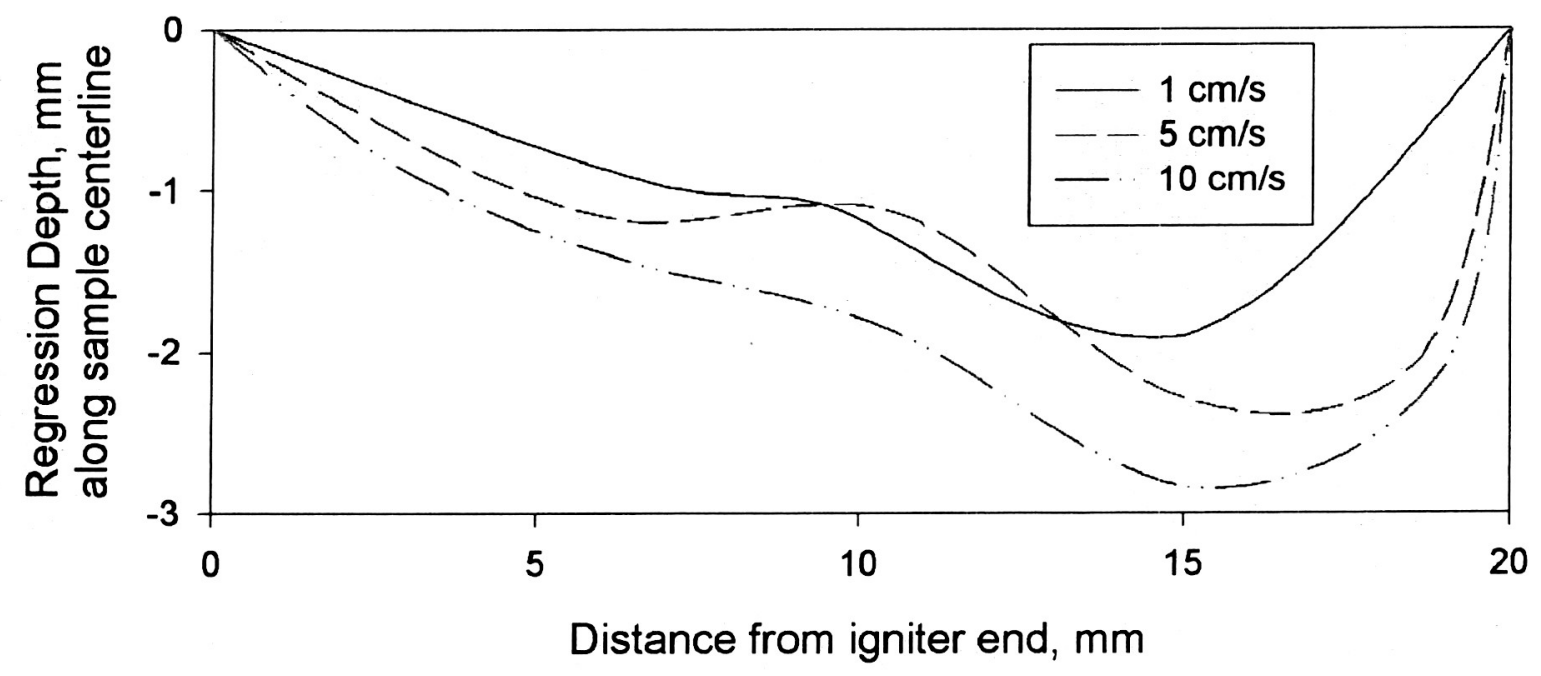

Figure 15 


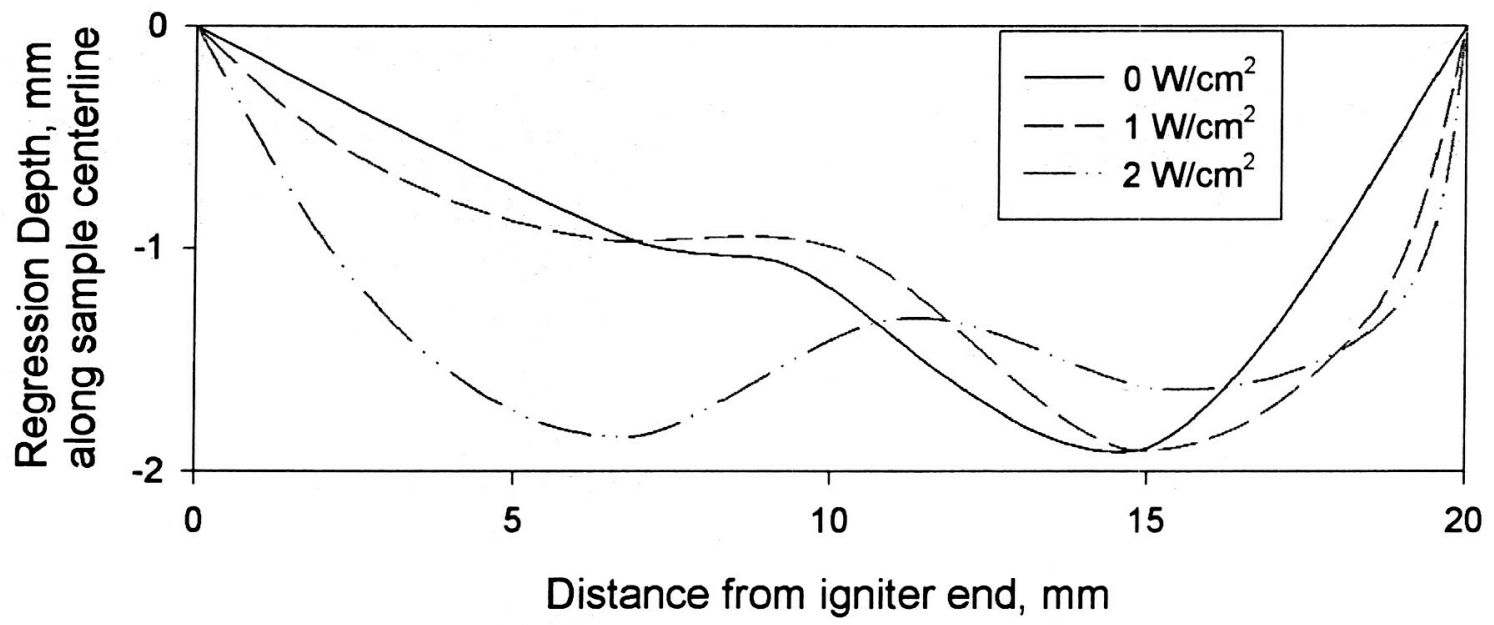

Figure 16 


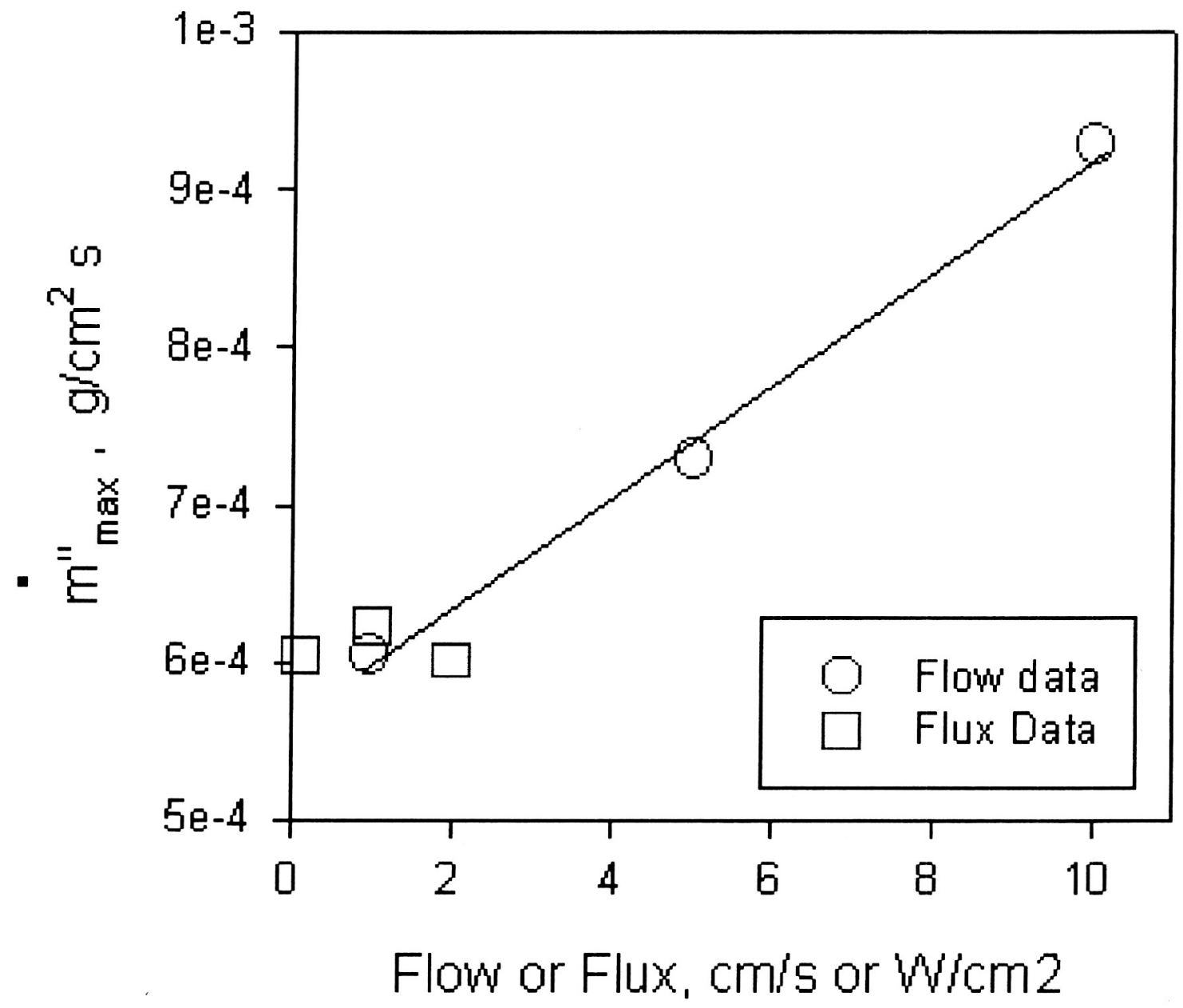

Figure 17 


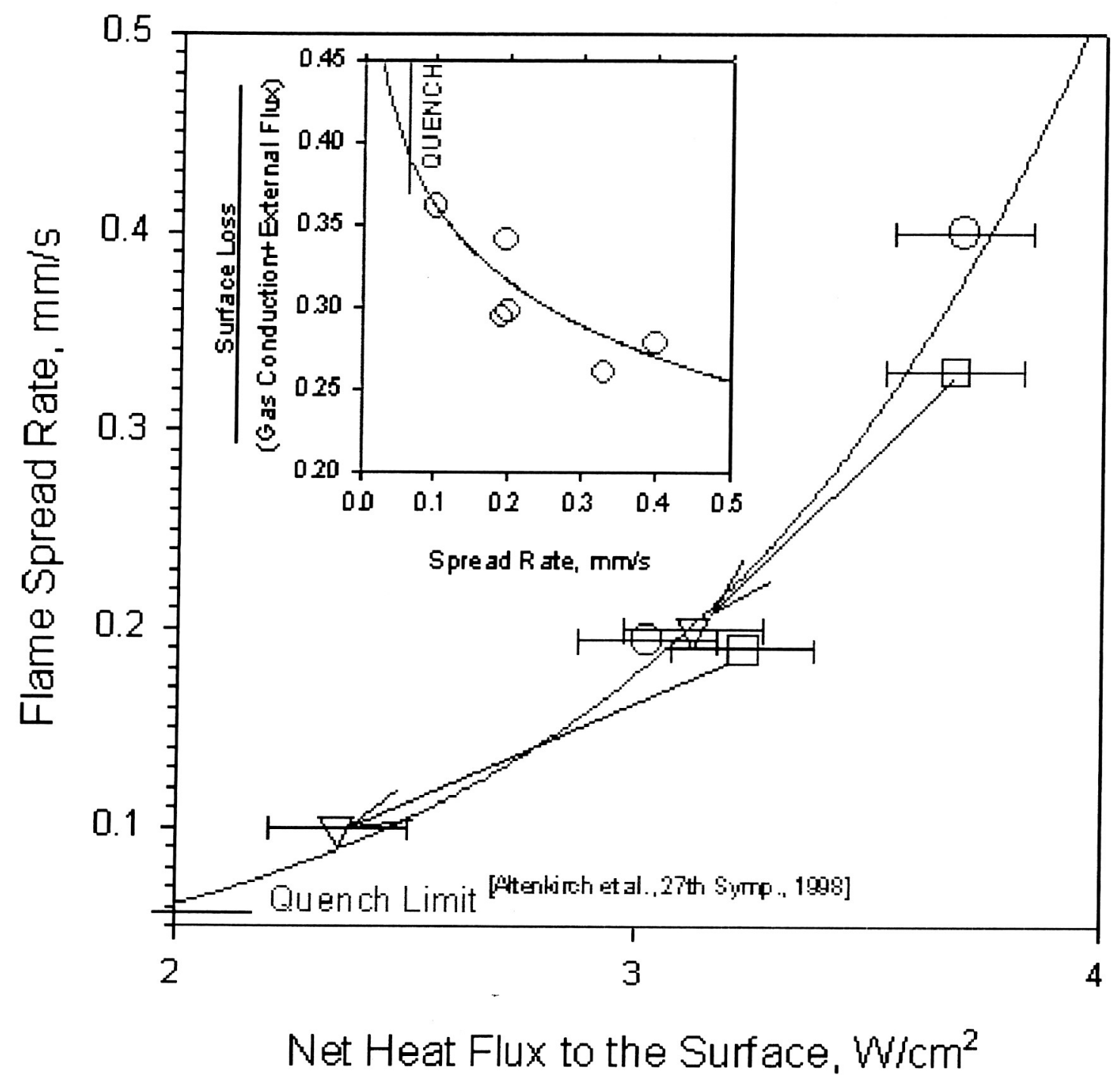

Figure 18 


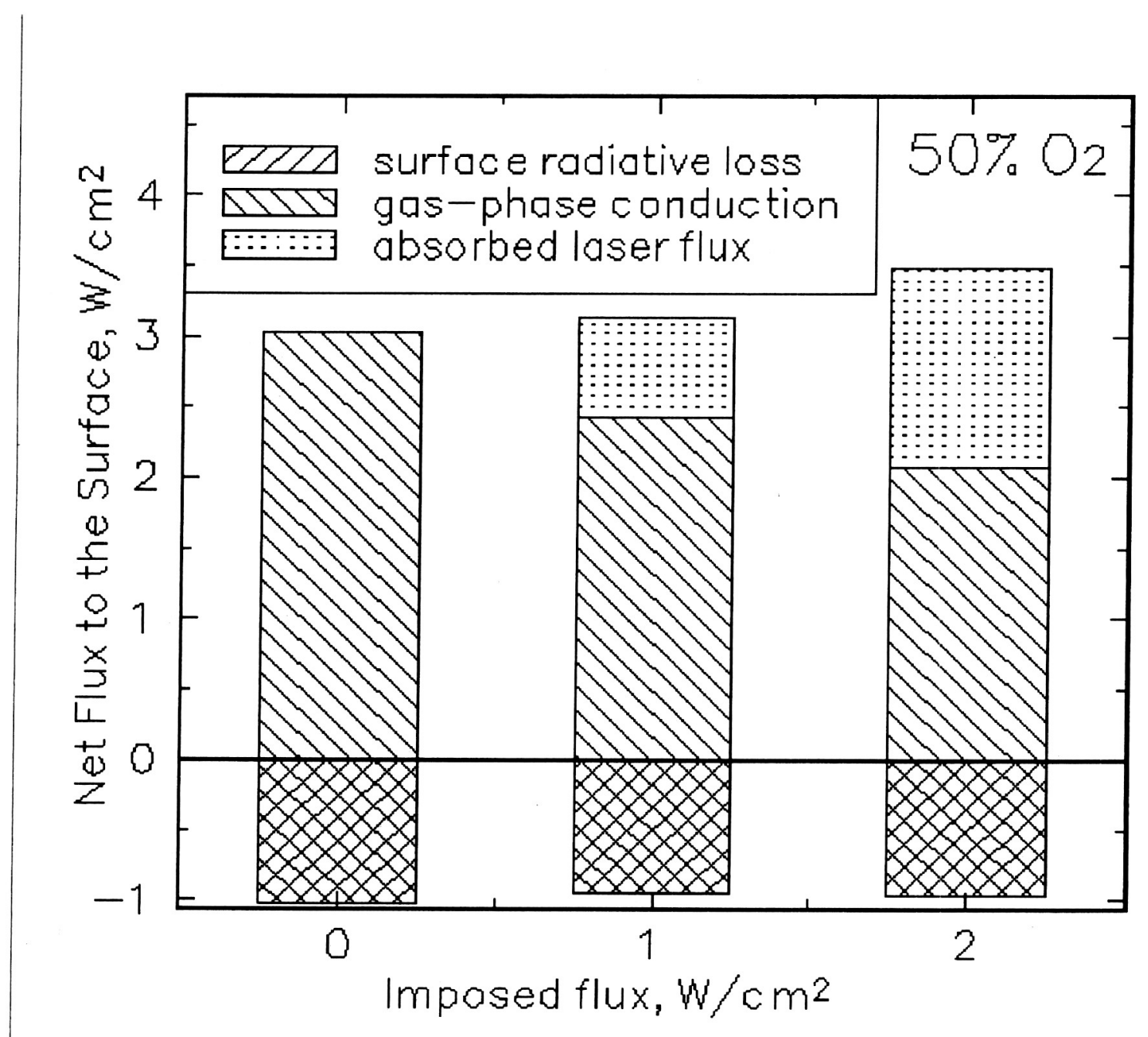

Figure 19 

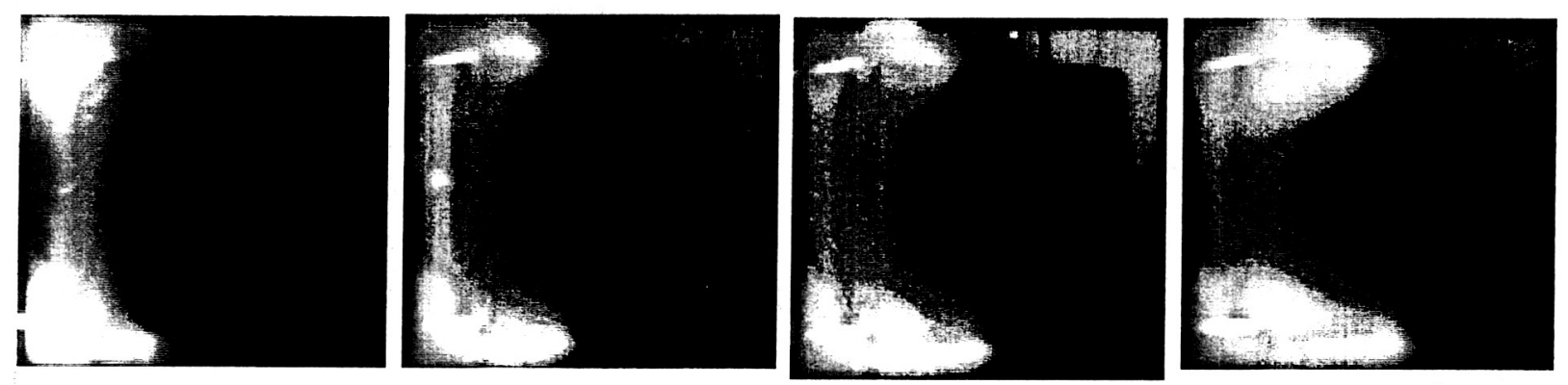

Figure 20a
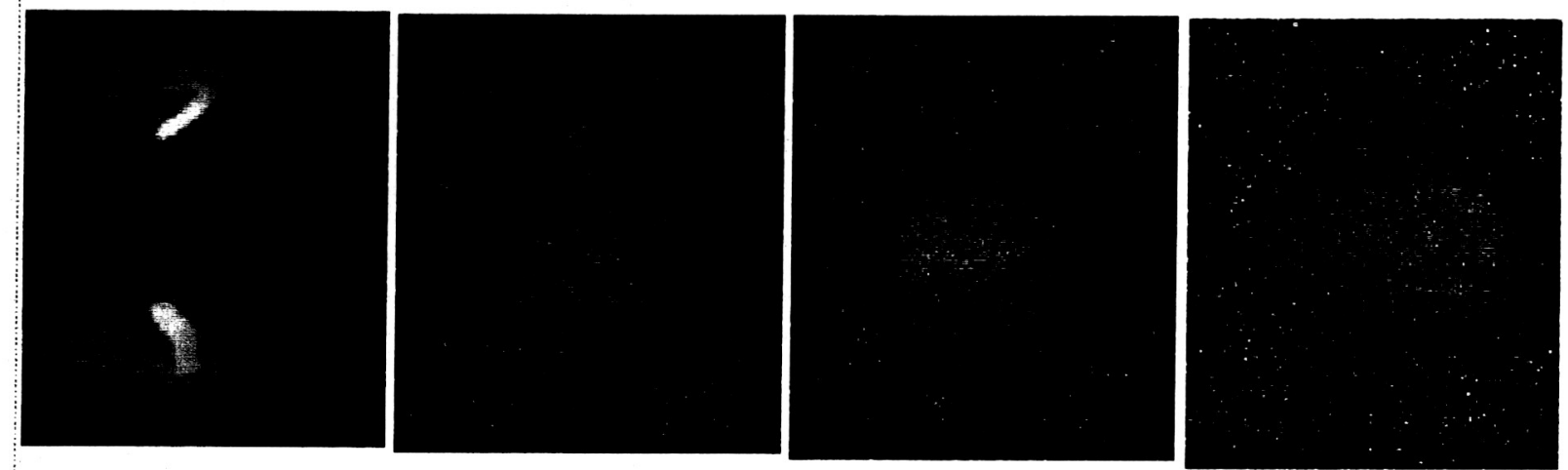

Figure 20 b 


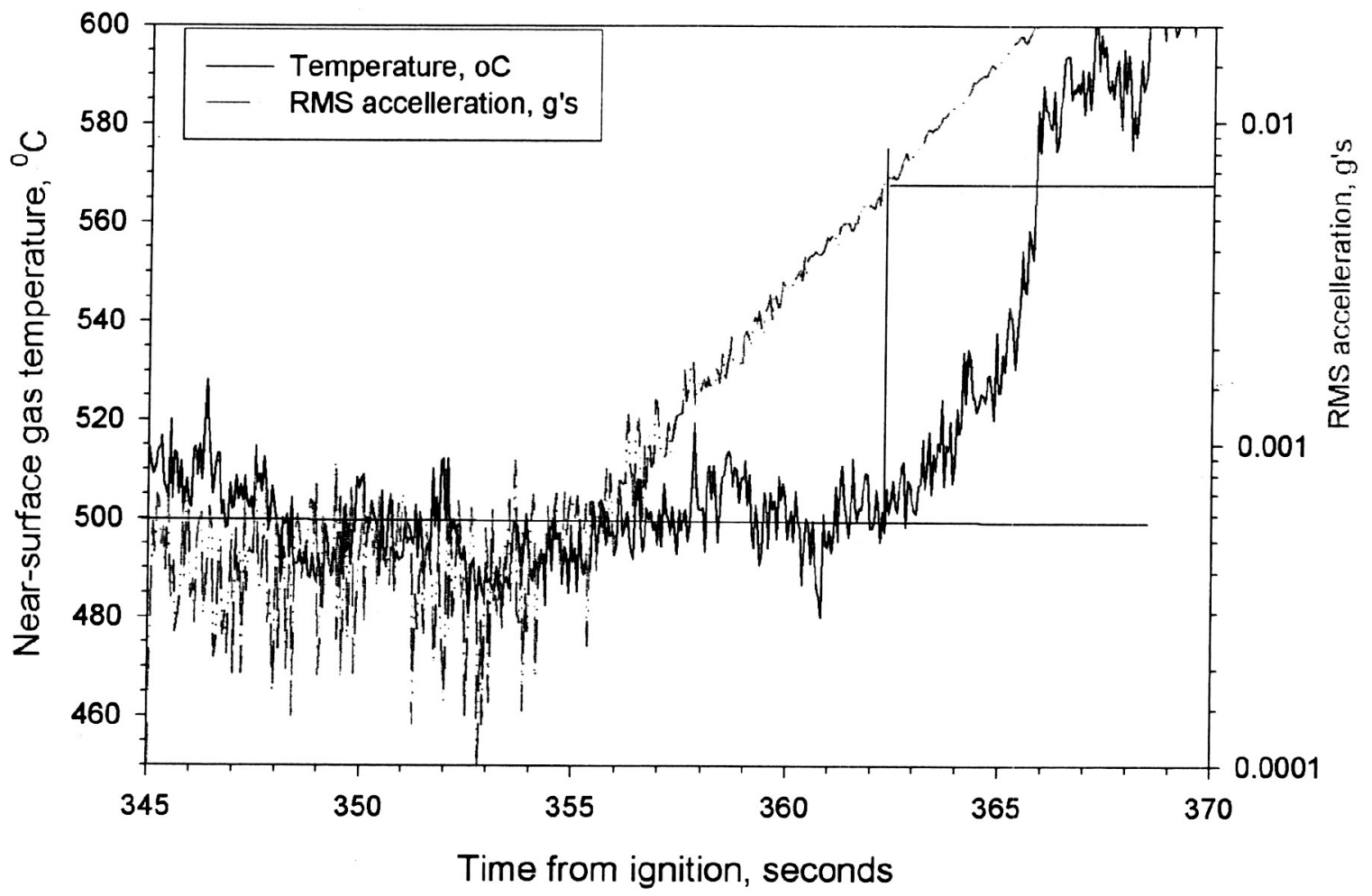

Figure 21 
Table 1

DARTFire Test Matrix

\begin{tabular}{|l|l|l|l|l|}
\hline $\begin{array}{l}\text { Flight - } \\
\text { Tunnel }\end{array}$ & $\begin{array}{l}\text { Molar Oxygen } \\
\text { Concentration, \% }\end{array}$ & $\begin{array}{l}\text { Bulk Flow } \\
\text { Velocity, cm/s }\end{array}$ & $\begin{array}{l}\text { Imposed Radiant } \\
\text { Flux, W/cm2 }\end{array}$ & $\begin{array}{l}\text { Measured spread } \\
\text { rate, cm/s }\end{array}$ \\
\hline 1A & 35 & 1 & 1 & Extinguished \\
\hline $\begin{array}{l}\text { 1B } \\
\text { baseline) }\end{array}$ & 50 & 1 & 0 & 0.020 \\
\hline 2A & 50 & 1 & $1^{*}$ & $\begin{array}{l}0.019 \text { on } \\
0.010 \text { off }\end{array}$ \\
\hline 2B & 50 & 5 & 0 & 0.032 \\
\hline 3A & 50 & 1 & $2^{+}$ & $\begin{array}{l}0.033 \text { on } \\
0.020 \text { off }\end{array}$ \\
\hline 3B & 50 & 10 & 0 & 0.045 \\
\hline 4A & 50 & 1 & 1 & No Ignition \\
\hline 4B & 70 & 1 & 0 & 0.040 \\
\hline
\end{tabular}

selected to $\sim$ offset surface radiative loss

${ }^{+}$selected to $\sim$ offset surface+ gas-phase radiative loss 
Table 2

Burning Rate Data

\begin{tabular}{|l|l|l|l|l|l|}
\hline Test No. & $\begin{array}{l}\text { Flow } \\
\mathrm{cm} / \mathrm{s}\end{array}$ & $\begin{array}{l}\text { Flux, } \\
\mathrm{W} / \mathrm{cm}^{2}\end{array}$ & $\begin{array}{l}\text { Total mass } \\
\text { Lost, } \mathrm{g}\end{array}$ & $\begin{array}{l}\text { Deepest } \\
\text { regression, } \\
\mathrm{mm}, \mathrm{r}_{\max }\end{array}$ & $\begin{array}{l}\text { max. burning rate } \boldsymbol{X}, \\
\mathrm{g} / \mathrm{cm}^{2} \mathrm{~s}\end{array}$ \\
\hline $1 \mathrm{~b}$ & 1 & 0 & 0.162 & -1.90 & $6.04 \times 10^{-4}$ \\
\hline $2 \mathrm{a}$ & 1 & 1 & 0.121 & -1.90 & $6.23 \times 10^{-4}$ \\
\hline $2 \mathrm{~b}$ & 5 & 0 & 0.190 & -2.23 & $7.29 \times 10^{-4}$ \\
\hline $3 \mathrm{a}$ & 1 & 2 & 0.179 & -1.84 & $6.02 \times 10^{-4}$ \\
\hline $3 \mathrm{~b}$ & 10 & 0 & 0.196 & -2.84 & $9.28 \times 10^{-4}$ \\
\hline
\end{tabular}

$\boldsymbol{x}$ maximum burning rate $=\rho r_{\max } /$ total burn time 
Table 3

Surface Energy Balance (Eqn. 1)

\begin{tabular}{|c|c|c|c|c|c|}
\hline $\begin{array}{l}\text { Imposed } \\
\text { Laser } \\
\text { Flux, } \\
\text { W/cm }\end{array}$ & $\begin{array}{l}\text { Absorbed } \\
\text { Laser Flux, } \\
\text { W/cm } \\
(\alpha=0.8)\end{array}$ & $\begin{array}{l}\text { Conductive } \\
\text { Flux, W/cm } \\
\text { (gas-phase } \\
\text { thermocouples) }\end{array}$ & $\begin{array}{l}\text { Surface Loss, } \\
\text { W/cm² } \\
\text { (radiometer) }\end{array}$ & \begin{tabular}{|l} 
Net \\
Flux, \\
W/cm²
\end{tabular} & $\begin{array}{l}\text { Flame } \\
\text { spread rate, } \\
\mathrm{cm} / \mathrm{s}\end{array}$ \\
\hline $0\left(50 \% \mathrm{O}_{2}\right)$ & 0 & 4.05 & 1.03 & 3.02 & 0.020 \\
\hline $1\left(50 \% \mathrm{O}_{2}\right)$ & .8 & 3.38 & 0.95 & 3.23 & 0.019 \\
\hline $1\left(50 \% \mathrm{O}_{2}\right)$ & 0 (off) & 3.2 (further) & 0.85 & 2.35 & 0.010 \\
\hline $2\left(50 \% \mathrm{O}_{2}\right)$ & 1.6 & 3.04 & 0.96 & 3.68 & 0.033 \\
\hline $2\left(50 \% \mathrm{O}_{2}\right)$ & 0 (off) & 4.05 (closer-1b) & 0.93 & 3.12 & 0.020 \\
\hline $0\left(70 \% \mathrm{O}_{2}\right)$ & 0 & 4.73 & 1.03 & 3.70 & 0.040 \\
\hline
\end{tabular}

